\title{
CUADERNOS
}

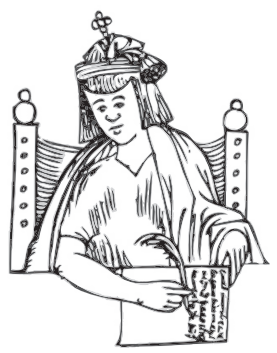

\section{UNIDAD POPULAR Y GOLPE MILITAR EN RAPA- NUI. INFORMES DE LA GOBERNACIÓN DE ISLA DE PASCUA (JUNIO Y OCTUBRE DE 1973)*}

\author{
Rolf Foerster** \\ Sonia Montecino ${ }^{* * *}$
}

“...los isleños viven con el corazón puesto en la Polinesia y el estómago en Santiago"1

Resumen: Dos documentos elaborados por la Gobernación de la Isla Pascua (en junio y octubre de 1973) permiten aproximarse y problematizar el empoderamiento y agencia de la comunidad rapanui, pre y post Golpe Militar, como también algunas de las razones de la valoración positiva del Gobierno de Pinochet.

Palabras Clave: Isla de Pascua, comunidad rapanui, economía isleña.

\section{POPULAR UNITY AND MILITARY COUP IN RAPA-NUI. REPORTS FROM THE GOVERNORATE OF EASTER ISLAND (JUNE AND OCTOBER 1973)}

ABSTRACT: Two documents prepared by the Governor of Easter Island (June and October 1973) allow us to approach and question the empowerment and

* Este trabajo se enmarca en el Proyecto Fondecyt No 1170422: "Los procesos de colonialidad en Rapa Nui y sus empoderamientos durante la Ley Pascua (1966-1993)".

** Departamento de Antropología. Universidad de Chile. Correo electrónico: rolf22@gmail.com

*** Departamento de Antropología. Universidad de Chile. Correo electrónico: smonteci@uchile.cl

1 Carta del 3/2/1974 en El Mercurio de Mario Godoy Q. 
agency of the Rapanui community, pre and post Military Coup, as well as some of the reasons for the positive assessment of the Pinochet Government.

KEY WORDS: Easter Island, Rapa Nui, Popular Unity and Military Coup, Colonialism.

Recibido: julio 2017

Aceptado: septiembre 2017

\section{Introducción}

$\mathrm{A}^{\mathrm{t}}$

través de dos informes sobre Isla de Pascua, elaborados desde su Gobernación, podemos aproximarnos a un balance de las políticas de la UP, y al mismo tiempo al grado de "empoderamiento de la comunidad". Esto último debido a su creciente control de la economía local, y a su participación política, al ser parte sustancial del Consejo Departamental de Desarrollo (CDD) y participar en el Comité Coordinador de Administración (CCD). También es posible acercarnos a las medidas represivas tomadas por la jefatura militar post-golpe, que en primera instancia no afectaron a la comunidad sino a los funcionarios del aparato administrativo, la gran mayoría continentales, sin redes parentales hacia el interior de la Isla, pero al menos con dos excepciones: Mario Arévalo, casado con Bernarda Pakarati Tepano y Víctor Acuña, con María Pakarati Ika.

El primer informe data del 11 de junio de 1973 y da cuenta de las “...obras y actividades desarrolladas por los diferentes organismos dependientes del Ejecutivo en el Departamento". El segundo es del 19 octubre, casi un mes después del Golpe de Estado, realizado por el nuevo Gobernador de la Isla, el Mayor de Carabineros Omar Fuenzalida, que hace una memoria de las actividades administrativas.

Estos dos informes deben leerse de manera complementaria, sobre todo porque el segundo desarrolla un balance sobre la comunidad que el primero no incluye de forma explícita, aunque aporta datos cruciales sobre la economía "familiar" rapanui. Una economía que se ligaba al aparato administrativo, a la industria del turismo y al comercio, tornando visible que la competencia entre los continentales (tire) y la Cooperativa Multiactiva era acentuada. El informe del mayor Fuenzalida no solo se dirigía contra los ex miembros de los Comité de la Unidad Popular (CUP), sino también contra la comunidad rapanui y su participación política en el Consejo (CDD) y en el Comité (CCD). Se trataba de manera clara de revertir el empoderamiento comunitario y de chilenizar, en el sentido de que los rapanui -en los términos del epígrafe-pusieran su corazón en Chile.

La política de ODEPLAN post golpe, bajo el mandato de Roberto Kelly, fue dar continuidad al Consejo y al Comité, profundizar la rapanuización de las instituciones estatales continentales o tire y sostener que era totalmente factible ser chileno y rapanui, tal vez por medio de un acuerdo tácito de no entregar tierras a los continentales. Posiblemente la figura de Sergio Rapu Haoa sea la más emblemática de ese nuevo 
paradigma: arqueólogo destacado², director del Museo (desde 1972), aplicó la lógica de fortalecer Isla de Pascua y su comunidad, estrechando los/sus vínculos con el Estado de Chile, lo cual le valió ser designado en 1984 el primer Gobernador rapanui, como con la Polinesia, logrando la participación rapanui en los festivales que allí se celebraban.

En base a estos antecedentes, adicionales a los que publicamos en $2013^{3}$, se puede sostener que con la UP se fortaleció el poder interno, sobre todo porque éste no se ligó al sistema partidario (aun cuando hubo una militancia de muchos rapanui en los partidos políticos de izquierda ${ }^{4}$ ), lo que explica la sorpresa manifestada en el informe de octubre de 1973. Se podría decir que el Golpe de Estado fue contra los tire, no contra los rapanui. Sin embargo, hay que realizar dos observaciones: en el período de los gobernadores Carlos Bastías y Omar Fuenzalida (de septiembre de 1973 a agosto de 1974), la represión, como veremos, también se ejerció contra sectores de la comunidad. La segunda: que en la dictadura el proceso de rapanuización de las instituciones fue un proceso generalizado, aunque favoreció a algunas familias 5 .

\section{El informe de julio de 1973}

Este informe da cuenta de las obras realizadas por la diversas instituciones del Estado y, en algunos casos, precisa sus necesidades: la Oficina Departamental de Obras Públicas, la mantención del Aeropuerto de Mataveri, la construcción de bodegas y de local de venta; la Dirección de Obras Sanitarias, el abastecimiento de agua, desalinizar los pozos y análisis bacteriológicos; la Corfo, sobre los servicios eléctricos, mantención y reparación de muelles y bodegas; la instalación de tres cámaras frigoríficas; la CorfoVaitea, el aumento del ganado vacuno, estabilidad del ganado ovino en 25.000, huerto hortícola y frutal; programa forestal; protección arqueológica cercando el Rano Raraku; de Entel, instalación de Radio Estación, construcción de una Oficina terminal; CONAF y su programa de forestación; la Oficina de Tierras y Colonización y su quehacer sobre la división de parcelas en el área rural y de subdivisión de sitios e hijuelas en el sector

2 No solo por su vinculación con Heyerdahl, sino por ser el arqueólogo que rescató y puso los ojos a los moai y con ello los hizo renacer: "Hoy en día, el ojo ya se puso... eso significa que en la cultura Rapa Nui, el Moai vive al igual que el ser humano " (Ana María Tuki); "Cara viviente, con los ojos es cara viviente" (Tamuro Pakarati) (Rescatando el patrimonio cultural material Rapa Nui, F.N.D.R., 2016, pág. 30).

3 Foerster y Montecino, 2013, pp. 56-116.

4 Para sorpresa de los políticos tire, los rapanui, en última instancia se plegaban al mandato de la comunidad: un ejemplo de ello fue el asunto de los pagos de luz.

5 El informe de Sergio Jarpa, comandante del Beagle, fechado en mayo de 1978, señala que: "Con respecto al Alcalde Sr. Edmond (sic) consideran que él junto con los otros socios de Mahinatur constituyen los millonarios de la Isla y explotan al resto de los Pascuenses con quienes no se mezclan por considerarse superiores en cultura y costumbres. Este grupo económico esta formado por el $\mathrm{Sr}$. Orlando Paoa, dueño de la hostería Hotu Matua, el Sr. (Ab.) Benito Rapahango, miembro de la Armada y actualmente destinado a la Capitanía de Puerto de la Isla, el Alcalde Sr. Juan Edmond, su hermano Jorge Edmond y el Sr. Pablo Haoa" (Archivo de la Intendencia, Caja 1978, Nº 611-612). 
urbano ${ }^{6}$; el Banco del Estado y la creación de la Caja de Cambios Internacionales, nuevo local, etc.; Carabineros de Chile y el mejoramiento de las viviendas de su sector; Armada y su registro de embarcaciones que recalaron en la Isla; sobre el Cantón de reclutamiento y su mínima cuantía, esta labor podría anexarse a otro Servicio"; LAN Chile da cuenta del movimiento en 1972: 3.685 pasajeros arribados y de carga llegada a la Isla: 328 toneladas; la oficina de Correos y Telégrafos (en 1972 su movimiento de correspondencia fue de 32.552 piezas postales); SAG, la fumigaciones con dos aviones y la lucha contra el chamico; HONSA, Hotel Hangaroa (60 habitaciones); y ECA su misión de proveer de los alimentos necesarios.

Complementan este Informe, varios cuadros que son muy iluminadores: el primero, relativo al número de continentales y de rapanui que trabajaban en los servicios estatales. El dato revelador es el siguiente: de los 306 “funcionarios", contratados por los 25 servicios, 127 son continentales y 179 rapanui. Añádase el grupo familiar: 346 continentales (141 corresponden a los familiares de los carabineros) y 611 rapanui. Esto significa, entre otras cosas, que casi la mitad de la población obtiene parte de sus ingresos por esta vía ${ }^{7}$. Veremos con el informe de Omar Fuenzalida la pugna rapanui por esos trabajos. La clave de esta "política" radica en lo ya señalado por Mc Call: “...los rapanui utilizan la palabra mauku para referirse a cualquier chileno, pero especialmente a los que trabajan como empleados públicos. La población no se opone a que existan cargos en esos servicios, pero objetan el hecho de que no estén ocupados por isleños o personas relacionados con ellos" $"$.

El segundo y tercer cuadro, que presenta datos hasta febrero de 1973, aportan antecedentes sobre las "empresas de transportes y particulares que ejercen el comercio de turismo" y los “dueños y detalles de hospederías". Su lectura presenta algo evidente: la industria del turismo estaba controlada por los rapanui, con una altísima participación de las mujeres (de las 13 residenciales, 11 están a su cargo). ¿Se desprende de esto que los hombres trabajan en las instituciones estatales? Al parecer sí. Este punto es crucial, ligado al impedimento de que tire o extranjeros sean propietarios de tierras, y distingue a Rapa Nui de Tahiti y Hawái. En pocas palabras: el motor de la economía rapanui, el turismo, está dominado por las isleñas abriendo interesantes interrogantes sobre su posición y condición en la sociedad rapanui del periodo.

El cuarto y último cuadro, "Continentales y extranjeros que se han establecido en el Depto. Isla de Pascua”, permite complejizar los anteriores: el comercio aparece como el lugar donde se localiza la inversión continental. Y nuevamente McCall es una ayuda para ponderar este asunto: "Solamente 8 de los 25 pequeños negocios que operan en

6 Subsiste el problema del Plano Regulador, aprobado pero cuestionado al mismo tiempo por la Municipalidad, la que expresa su desaprobación no aprobando el Plano de Loteo.

7 Estos números, como lo planteado por McCall para mediados de los 80 , donde “...cerca de tres cuartos de la población total de rapanui trabaja en alguna rama de las instituciones del gobierno o depende de alguno que lo hace...", le permite decir que estamos frente a una "espiral de dependencia" (1998: 109).

8 Mc Call, (1996-a), pp. 38. El destacado es nuestro. 
la isla de Pascua pertenecen a chilenos continentales. La mayor parte de la actividad comercial está en manos rapanui" 9 .

Nuestra tesis es que la activa participación rapanui en lo económico es correlativa a su implicación política. Esta situación no ha sido visibilizada por los estudiosos (McCall, Cristino et al., Porteous, Delsing), lo que resulta sorprendente sabiendo que en la época de la Unidad Popular se dio un giro a la ley 16.441 con la creación, en agosto de 1971, por medio del decreto ley 1.339, de la Comisión Nacional Asesora para el Departamento de Isla de Pascua (CONADIP), del Comité Coordinador de Administración (CCD) y del Consejo Departamental de Desarrollo (CCD). Recordemos que los objetivos de esta institucionalidad eran "que para una adecuada administración de la Isla de Pascua... es indispensable la participación de los isleños”.

Miembros del Consejo Departamental de Desarrollo (septiembre de 1971) ${ }^{10}$

\begin{tabular}{|l|l|}
\hline Gobernador de Isla de Pascua & \\
\hline Alcalde de la Comuna & Rafael Tuki Tepano \\
\hline Representante de Odeplan & Edmundo Edwards Eastman \\
\hline Representación de Dirección de Turismo & (aún no designado) \\
\hline Junta de Vecinos: & Juan Chávez \\
\hline & Policarpo Ika Paoa \\
\hline & Ricardo Tuki Beri Beri \\
\hline De los Centros de Madres & Margarita Pakarati Tuki \\
\hline Director de la Escuela & Jacobo Hey Paoa \\
\hline Consejo Local de Deportes & Zorababel Fati Teao \\
\hline Junta de Vigilancia de Monumentos & Juan Haoa Hereveri \\
\hline Representante de trabajadores rurales & Arsenio Rapu \\
\hline Representante de trabajadores urbanos & Germán Hotus Chávez \\
\hline Comité Coop. Agropecuario & Alfonso Rapu \\
\hline Comité Coop. Pesca & Regino Calderón Calderón \\
\hline Comité Coop. Turismo-Transporte & Benito Rapahango \\
\hline Comité Coop. Artesanos & Nicolás Pakarati \\
\hline Comité Coop. Artistas & Florencia Atamu Hotus \\
\hline Comité Coop. Comercio y abastecimiento & No designado \\
\hline
\end{tabular}

¿Fue el Consejo una realidad participativa de la comunidad, o fue un volador de luces, una pantalla democrática sin efectos? Conociendo la trayectoria política de los integrantes de este primer Consejo -compuesto por la elite de la revolución de 1964-66- se puede concluir que no fue un simple disfraz. Por otro lado, la documentación, que hemos podido encontrar de las reuniones del Consejo, evidencia que allí se trataban los grandes temas de la Isla. Por ejemplo, una "minuta" del año 1971, entre agosto y noviembre, nos

9 Ídem, pp. 37.

10 En Archivo Alfredo Tuki. 
permite conocer los “Acuerdos del Consejo Departamental de Desarrollo con solución en estudio". Veamos tres para aproximarnos a su quehacer:

Sesión 30 de agosto: 1.- Se acordó solicitar intervención del Estado para rescatar bienes culturales, mantenerlos en custodia hasta contar con Museo Adecuado; 2.- Reintegrar a la Isla, colección cedida por el Sr. Edwards, al Centro de Estudios Antropológicos U. de Chile; 3.- Gestionar ante el Sr. Obispo y la Superioridad de la Orden, entrega biblioteca Rev. Padre Sebastián Englert; 4.- Se plantea por la necesidad de instalar una Oficina del Servicio de Seguro Social.

Sesión 13 septiembre: 1.- Se acuerda encargar estudio materiales aptos para fabricar arena a Obras Públicas según resultado, Planta Chancadora podría ser usada por la población en horas fuera de faena de servicio; 2.- Sector Agropecuario, acuerdos para implantar gallineros, mejorar praderas, mejorar ganado vacuno y crear en la Oficina local del Banco del Estado, el Departamento Agrícola; 3.- Solicitar a S.N.S. una ambulancia para el Hospital Hanga Roa.

Sesión 27 octubre: 1.- Acuerdo capacitación isleños, para labores de Entel, por medio de INACAP; 2.- Acuerdo solicitar a C. Nacional Asesora cumplimiento programa de Desarrollo Social; 3.- Inversiones de personas naturales chilenas en Isla de Pascua, sólo asociados con isleños a Coop. locales. No se aceptan capitales ni empresas extranjeras ${ }^{11}$.

El Consejo lograba así “acuerdos" para solicitar, gestionar, encargar, agilizar, sugerir, la intervención de los servicios del Estado con el fin de "mejorar" sus prestaciones en áreas que la comunidad (sus representantes) consideraban pertinentes. Pero, también exige que: "Inversiones de personas naturales chilenas en Isla de Pascua" estén “... asociados con isleños a Coop. locales", asimismo que "No se aceptan capitales ni empresas extranjeras".

Lamentablemente, no tenemos las actas de los consejos del año 1972, y en el año 1973 solo un memorándum, para la sesión del mes de julio, y las dos últimas actas antes del Golpe de Estado. En julio, los temas tratados fueron: solicitar alambrados que rodeen los conos volcánicos; se cuestionó la adquisición y el pago acordado al terreno y mejoras del aérea destinada al fututo museo, con el argumento de que las tierras de isleños no se pueden vender y, consecuentemente, se comentó el reciente caso de donación de tierras hecho por un isleño a la Compañía LAN. Hay un debate sobre el alza del precio de la langosta y pescado, para ello se acuerda "armonizar los precios propuestos por el Comité Pesquero y los de la I. Municipalidad". Se informa al Consejo de la paralización del Fundo Vaitea por incumplimiento de reajuste del $200 \%$. Ahora bien, el tema principal del Consejo, fue las "dificultades en la extracción de escoria del cerro Tararaína", debido a la "presunta propiedad hecha por la viuda e hijos de don Santiago Pakarati”. El Consejo estimó: “a) por derechos de tradición 
el cerro estaba incluido en los terrenos que el Sr. Pakarati recibió de su suegro Juan Tepano, y fue cultivado hasta 1962; b) en el año 1968, por disposición de la Oficina de Tierras pasó a ser fiscal a pesar de no existir la notificación que debió hacerse al propietario; c) El Consejo por unanimidad apoya la familia en su reclamación para que se le otorgue una compensación, pero deja establecido que este apoyo es por la generosa y permanente contribución que durante toda su vida dispensó el Sr. Pakarati a cualquier obra de bien público"12.

A la sesión del Consejo, del martes 14 de agosto de 1973, asistieron: Moisés Sudy (Gobernador); Sebastián Pakarati (Alcalde); Arsenio Rapu Púa (Pdte. Cooperativa 'Rapa Nui'); Juan Chávez H. (Junta de Vecino); Policarpo Ika (Junta de Vecino); Ricardo Tuki H-V. (Junta de Vecino); Alfonso Rapu Haoa (Comité de Turismo Coop.); Luis Paté Paoa (Comité Artístico Coop.); Melchor Hucke Hill (Rep. Obreros Rurales); Mario Arévalo (Rep. Odeplan y Sect.). En Santiago: Miguel Teao (Pdte. Coop. Te Pito). Becado en U.S.A. Sergio Rapu (J. Vigilancia de Monumentos). No asistieron: Regino Calderón (Comité de Pesca Coop.); Lucas Riroroko (Reempl. Sr. Calderón); Germán Hotus Chávez (Rep. Obreros Urbanos); Nicolás Haoa H. (V. I. Depta., enfermo) y Sra. Margarita Pakarati (C. de Madres). Los temas tratados van desde la visita de barcos japoneses, de cómo celebrar las festividades del 9 y 18 de septiembre ("se acepta la sugerencia del Sr. Alcalde de que debe hacerse participar a toda la población”), protección de Orongo ("se proponen medidas inmediatas para el control de visitas a ese lugar y se sugiere que deben adoptarse medidas judiciales para proteger los sitios arqueológicos". En los "varios" la atención de ECA y la distribución de mercaderías; la queja de Alfonso Rapu por los daños ocasionados en Anakena por el Club de escaladores "La Reina"; sobre las pensiones de vejez y el estudio de la posibilidad de otorgarla a las personas mayores de 65; y por último, el problema de financiamiento que deben enfrentar los padres de escasos recursos cuyos hijos deben viajar a Antofagasta, invitados al festival de la canción.

Hemos reproducido el acta de la sesión del 11 septiembre por ser un documento histórico que atestigua el fin de una época. Fue escrita por el "compañero" Moisés Sudy Castro, Presidente del Consejo, Gobernador y General Carabineros. Los dos últimos párrafos tienen el tono dramático del fin de una etapa.

12 Archivo Gobernación Isla de Pascua, P1540173 y s. El memorándum esta firmado por Mario Arévalo (Representante de ODEPLAN en Isla de Pascua) y enviado a Gonzalo Martner, Ministro Director de ODEPLAN con fecha 20 de julio de 1973. 


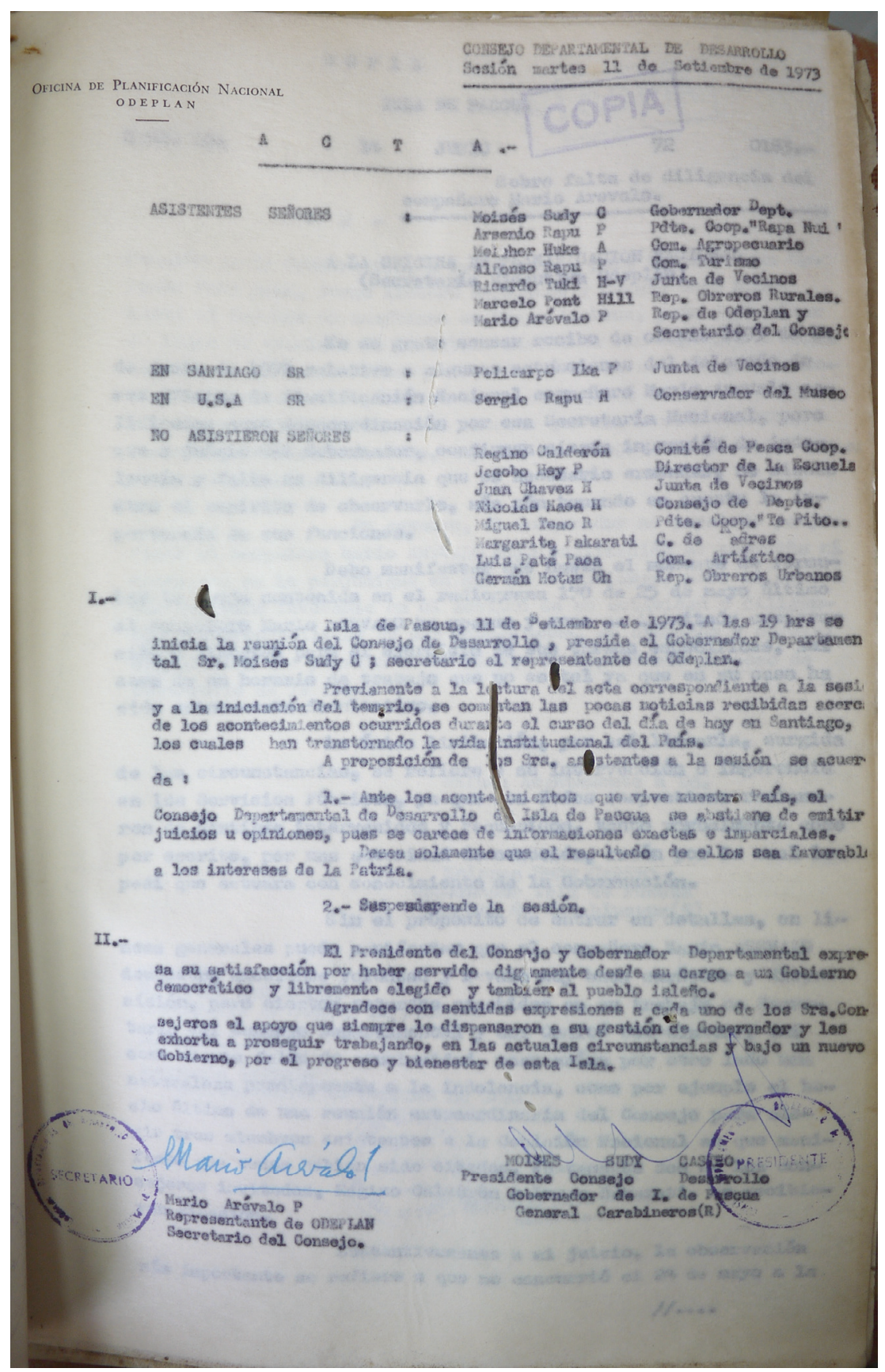

Archivo de la Gobernación de la Isla de Pascua (P1530953) 
¿Qué sucedió post septiembre de 1973? ¿Continuó esta política? Nuestra impresión es que se prolongó, pero no en un primer momento en que la Junta Militar que asumió la administración civil tenía la intención de revertir el proceso de empoderamiento y de chilenizar la isla por todos los medios.

\section{El informe de octubre de 1973 del mayor Omar Fuenzalida, alias el "Monje Loco"}

El 11 de septiembre, el Gobernador de la Isla de Pascua era el general de Carabineros Moisés Sudy Castro ${ }^{\circledR},{ }^{13}$ cuya simpatía con los partidos de la UP era explícita: en la correspondencia que mantenía con ODEPLAN el trato era el de "compañeros". Fue inmediatamente reemplazado por el capitán de corbeta (L) Carlos Bastías Alvarado ${ }^{14} \mathrm{y}$ éste a su vez sustituido, el 25 de septiembre, por el mayor de Carabineros Omar Fuenzalida Tobar. Paralelamente, se formó la "Junta Militar de Gobierno del Departamento de la Isla de Pascua” la que quedó conformada por Bastías, Fuenzalida y, como secretario, Benito Rapahango ${ }^{15}$.

Fuenzalida había llegado a la Isla en abril de 1972 y, como el más alto oficial de la $9^{\circ}$ Comisería de Pascua, estaba al tanto del funcionamiento institucional de la ínsula y de sus variados funcionarios. Su imbricación con el aparato institucional (como Comisario de Carabineros le correspondía participar en el CCD) y con la comunidad no fue menor y, por su carácter extrovertido y dicharachero, fue apodado el "monje loco".

$\mathrm{Su}$ "informe" de seis páginas, del 19 de octubre, es de carácter "reservado" y fue enviado al Ministro Director de ODEPLAN, capitán de navío Roberto Kelly Vásquez ${ }^{16}$. El objetivo era dar a conocer a la autoridad lo que "efectivamente" pasaba y de las medidas que se deberían tomar para revertir situaciones que consideraba inapropiadas y cuyo fundamento son las "experiencias del infrascrito en el lapso de un año y siete meses de permanencia en Isla de Pascua".

Fuenzalida valoraba negativamente a la Comisión de Desarrollo (con sede en Santiago) : “...estimo que fue dirigida en forma totalmente politizada por los señores Sergio Inzunza ${ }^{17}$, Lautaro Ojeda ${ }^{18}$, Gonzalo Martner y Oscar Santelices”. Se queja igualmente de que los informes que "estudian... son hábilmente preparados por personas interesadas, que no reflejan las condiciones existentes en la Isla por ir tras la busca de

13 Asumió la gobernación el 3 de marzo de 1972.

14 Era el capitán de puerto, cargo que asumió en mayo de 1971 (en ese entonces teniente $1^{\circ}$ ).

15 En 1995 se incorporó a la Escuela de Grumetes. Desde esa fecha se le considera como "marinero". Formó parte del primer CDD, como representante del Comité Coop. Turismo-Transporte.

16 Había estado en Pascua en marzo de 1966, al mando del buque escuela Esmeralda.

17 Subsecretario de Gobierno.

18 Lautaro Ojeda Herrera, Subsecretario de Tierras y Colonización. Desde fines de la década 40 formó parte de un movimiento a favor de la Isla de Pascua (fue integrante de la Sociedad de Amigos de la Isla de Pascua de Santiago y en 1954, su presidente). 
adeptos políticos y un paternalismo que lleva al pascuense a pensar que están sólo para recibir todo del fisco y no aportan nada en beneficio local y menos del país".

Descalifica la labor del Comité Coordinador de Administración (CCD), compuesto por 26 miembros, por ser 19 de ellos "marxistas", y además porque solo "podía intercambiar opiniones entre los Jefes de Servicio sin poder hacer valer sus apreciaciones sobre el Comité de Desarrollo (CDD), integrado en su totalidad por pascuenses".

Y sobre el Comité de Desarrollo su opinión es tan negativa que la única opción sería eliminarlo:

“...lo componen 19 personas elegidas por la Gobernación Departamental en forma irregular y arreglada [...] otros han sido elegidos por su clara tendencia izquierdista, tales como representes obreros Urbanos y Rurales.

Fuera de algunos capacitados de tendencia marxistas la mayoría son simples acompañantes que ocupan un asiento y no aportan absolutamente nada al desarrollo local, por el contrario entraban las reuniones al discutir necedades y darle gran importancia a circunstancias nimias.

Hay que atender que se debe a la poca capacidad intelectual y preparación de estos representantes isleños que son carentes de valores, manejables e interesados por lo material y hábilmente conducidos por los politiqueros" (p. 2).

Esta descalificación de los rapanui, como al borde de lo anómico e incompetentes, contrasta con la apreciación de sus capacidades económicas -en el turismo, la artesanía o en los trabajos de los servicios-, y políticas, ya sea persiguiendo que la Isla fuera un "fideicomiso de la Naciones Unidas o de Estados Unidos", o que formara parte de la "Confederación Polinésica", todo ello en concordancia con las "medidas segregacionistas" impulsadas por el Estado (Ley Pascua de 1966) ${ }^{19}$, y también con la intención de "ocupar puestos claves en la administración”:

El pascuense es económicamente poderoso, pese a su bajo nivel de vida, no le atraen las comodidades y por tal razón sus casas son de aspecto descuidado e incómodas, prefieren mal vivir antes de efectuar gastos en inmuebles o bienes de capital. Son corrientes los pascuenses con cuentas bancarias en monedas duras, en el extranjero como también tienen bienes en Tahiti, América y Europa.

El pascuense no se considera chileno, sino polinésico y en especial pascuense y aspira a que "su" isla sea un fideicomiso de las Naciones Unidas o de Estados Unidos de N.A. y se han detectado diversos movimientos en este sentido en los años 1964, 1969 y últimamente en 1972, hechos conocidos por el servicio de Inteligencia de la Armada, según informe del Capitán de Puerto Local.

19 Fuenzalida estaba al tanto del "Proyecto de Ley de Desarrollo de Isla de Pascua" (1972) que se tramitaba en el Congreso y, donde se establecía que es “....indispensable el preservar los terrenos de Pascua solo para los naturales isleños, lo que es importante para el mantenimiento de este pueblo, esto es con sus costumbres y tradiciones milenarias". 
Al no ser posible el fideicomiso, aspiran a formar parte de la Confederación Polinésica, como estado semi-independiente con Capital Federal en Tahiti.

Esperan la oportunidad de ocupar puestos claves y tener la administración de la isla, para alcanzar su objetivo, por tal razón crean el mito de la persecución del continental hacia ellos, lo cual es todo lo contrario y lo peor es que son apoyados por las medidas gubernamentales, en especial las segregacionistas tales como:

a.- Prohibición de ocupar cargos y trabajos, por continentales, habiendo pascuenses que puedan ejecutar esas labores, aunque sean de inferior calidad o rendimiento.

b.- Preferencia para los cargos a pascuenses, luego los matrimonios mixtos y en último lugar los continentales.

c.- Derecho exclusivo de ocupar terrenos en la isla, aduciendo su propiedad, olvidando que el pueblo chileno la adquirió legalmente pagando por ella y que sólo había 56 (sic) pascuenses moribundos cuando el Capitán Policarpo Toro tomó posesión de Isla de Pascua, en 1888.

d.- El proyecto de Ley para Isla de Pascua mantiene y aumenta este tipo de medidas segregacionistas.

e.- Prohibición del avecindamiento de chilenos continentales que puedan trabajar y entrar en competencia en sus monopolios de residenciales, empresas de turismo, transportes, agricultura y pesca.

f.- Persecución del continental que trata de establecerse en trabajos propios, salvo que se emplee como obrero de los pascuenses, a los cuales explotan y no les pagan, quedando luego abandonados e incapacitados de regresar al continente por el alto costo de los pasajes.

La visión (e intención) del gobernador Fuenzalida es de inversión "mítica": no son los rapanui los perseguidos, sino los continentales por éstos; como también decir que la "Isla es plácida y especial para mejorar de las afecciones nerviosas es un mito, creado por los turistas y los funcionarios comisionados a esta Isla que en realidad gozan los pocos días de su permanencia de las atenciones a que son objetos por parte de los funcionarios a quienes visitan, los tour por la Isla y demás atenciones propias de los pascuenses interesados. Pero la realidad es diferente, al poco estar viviendo se introduce en la vida ordinaria de la Isla, plagada de chismes, malas intenciones, egoísmos y acciones propias de pueblos chicos y como resultante se producen las neurosis depresivas y de angustia en un alto porcentaje".

Téngase presente que esta política rapanui anti colonial ha sido fundamental para configurar el tipo de "colonialismo" chileno en la isla y emerge como la marca propia del "acuerdo de voluntades de 1888": el "amigo del lugar" debe guardar distancia y permanecer ajeno a la isla (es lo que ha permitido que no se establezca una "colonia" tire).

Las medidas que se desprendían de este "diagnóstico" eran evidentes, no solo había que "sacar" de la isla a los "marxistas" sino también modificar el decreto ley 1.339 que había creado la Comité (CCD) y el Consejo (CDD). Si la comunidad se había empoderado con el Consejo también lo había hecho al no incentivarse la "empresa 
privada" en la que los rapanui no estaban capacitados. Otras medidas propuestas por Fuenzalida apuntaban a cuestiones que todas los gobernadores reclamaban: la falta de seguridad en el transporte, profesionales comprometidos, etc.

Ahora bien el "Informe confidencial" formaba parte de un dosier que incluía un conjunto de oficios reservados destinados a las autoridades para que iniciaran los trámites del traslado de los jefes de servicio y empleados, por ser "altamente politizados" y ser "dirigentes incondicionales de la Unidad Popular". La base de estos oficios es un documento "secreto" del 28 de septiembre, firmado por el gobernador Fuenzalida y enviado a la Intendencia de Valparaíso, donde se señala que:

"En relación al Oficio Secreto N ${ }^{\circ} 8$ de fecha 28 del actual de esta Gobernación, se solicita se comunique a los Servicios que corresponden el reemplazo de los funcionarios que se indican por ser elementos altamente politizados y que fueron dirigentes incondicionales de la Unidad Popular que dirigieron a su antojo los destino del Departamento de Isla de Pascua.

\section{Banco del Estado}

1.- Sr. Guillermo Tapia Offenhauser, agente, socialista, activo dirigente del ex CUP y tuvo gran injerencia en el Gobierno local y mantiene una actitud negativa sin llegar a ser delictuosa.

2.- Sr. Hugo Pertier, oficial administrativo, comunista, miembro del ex CUP, muy activo y resuelto.

3.- Sr. Amaro Inostroza Valenzuela, oficial administrativo, miembro del ex CUP, activo.

4.- Sr. René Pizarro Berrios, oficial administrativo, activo simpatizante de la UP formando equipo con los otros funcionarios.

5.- Sr. Félix Figueroa J., cajero, radical, activo simpatizante de la UP formando equipo con los otros funcionarios.

Este grupo de funcionarios se caracterizó por su unión y actividades políticas desarrolladas.

\section{Hospital}

6.- Dr. Mario Leguer Barrios, Medico director, de filiación Socialista y miembro del ex CUP local.

7.- Dr. Octavio Méndez Araya, dentista, socialista, el más activo dirigente del ex CUP, de gran influencia y antigüedad en la Isla.

8.- Sr. Víctor Acuña Vargas, practicante y laboratorista, Presidente del Partido Comunista, Regidor hasta el 11 de septiembre, miembro del ex CUP, Presidente de la Confederación de Trabajadores de Isla de Pascua, activo dirigente laboral, peligroso. 9.- Srta. Nora Núñez Miranda, matrona, socialista, componente del ex CUP femenino de Isla de Pascua, activa.

10.- Sra. Emilia Neveu Quiroz, auxiliar de enfermería, comunista, activa propagandista en la última elección parlamentaria. 
11.- Srta. Elizabeth Sepúlveda Vargas, auxiliar de enfermería, comunista, miembro del ex CUP femenino e ideóloga por familia (hija del Diputado por Valparaíso Sr. Sepúlveda) ${ }^{20}$.

\section{HONSA, Hotel 'Hanga Roa'}

12.- Javier Reinoso Reinoso, administrador.

13.- Teresa Carrasco Weber, oficial administrativo (cónyuge del Administrador).

14.- Ismael Monroy Silva, garzón y dirigente nacional de Sindicatos UP-Honsa.

\section{Empresa de Comercio Agrícola, ECA}

15.- Sr. Hermes Valenzuela, Agente, filiación radical y activo dirigente del ex CUP local.

16.- Sr. Melchor Hucke Atán, cajero, Consejero del Partido Comunista, activo dirigente, miembro del ex CUP y representante de la Cooperativa Multiactiva Rapa Nui y delegado ante el Comité de Desarrollo de Isla de Pascua.

17.- Lucas Pakarati Tepano, cajero.

\section{Obras Públicas y Transporte}

18.- José Donoso Contreras, Jefe Subrogante y Contador, filiación política Radical, activo miembro del ex CUP local, de gran importancia, dirigente laboral, organizador y Secretario de la Confederación de Trabajadores de la Isla de Pascua, actuando en conjunto con el Presidente del Partido Comunista local Sr. Víctor Acuña Vargas, del S.N.S. con larga trayectoria política en la Isla en el Gobierno de la UP.

\section{Instituto de Desarrollo Agropecuario, Indap}

19.- Sr. Roberto Orozco Canelo, jefe de aérea, filiación Mapu, ex Presidente del ex CUP en 1972 y actualmente activo dirigente y propagandista, de desempeño profesional totalmente deficiente y negativo.

20.- Sr. Francisco Uriarte Garcés, técnico pesquero, Mapu, activo UP, propagandista y de actuación profesional deficiente.

\section{Agencia Corfo Isla de Pascua}

21.- José Brusi Avendaño

\section{Empresa Agrícola CORFO Fundo Vaitea}

22. Arsenio Rapu Púa, empleado en comisión en INDAP y presidente Coop. Multiactiva "Rapa Nui".

23.- Marcelo Pont Hil, contador.

\section{Empresa Nacional del Petróleo}

24.- Carlos González, Jefe Terminal Petróleo.

Escuela coeducacional $N^{\circ} 1$ Isla de Pascua.

25.- Jacobo Hey Paoa, Director.

26.- Marcela Novoa Orellana, profesora, cónyuge de Lucas Pakarati, Cajero de ECA. 27.- Amanda Guzmán Solarzo, profesora, cónyuge de H. Valenzuela, Agente de la ECA.

20 Posteriormente se agrega al listado a "Sra. María Elena Riquelme, auxiliar de enfermería, activa simpatizante de la UP local y contraria al espíritu que anima a la Junta de Gobierno". 


\section{Corporación Nacional Forestal, Conaf.}

28.- Roberto Ramis Olivares, administrador.

Todos estos funcionarios fueron trasladados a Isla de Pascua durante el Gobierno de la Unidad Popular y con fines de adoctrinar y tomar control de la población”21.

De los rapanui mencionados en este oficio "secreto", al parecer el único "trasladado" fue Jacobo Hey y la documentación de la que hasta ahora disponemos no permite saber que otros rapanui estuvieron afectados por las medidas de la "Junta Militar" local ${ }^{22}$. Se desprende de una carta fechada a fines de abril de 1972, que al parecer hubo un número significativo de "exonerados". En ella, el gobernador Fuenzalida da la autorización, al Fiscal de Obras del Aeropuerto Mataveri, Juan Caamaño, para la contratación de parte de los exonerados:

1.- Atendiendo que las fuentes de trabajo en la Isla de Pascua son escasas y la mayoría es en las Obras Públicas.

2.- Que actualmente existen numerosos obreros sin ocupación por haber sido exonerados de sus cargos por sus actividades políticas antes del 11 de septiembre.

3.- Que es necesario ocupar estas personas para sustento de sus familiares.

\section{SE AUTORIZA}

La contratación de estos obreros en las diversas obras que se ejecutan en la Isla, pero sujetos a las siguientes condiciones:

A.- Contrato de trabajo condicionados a: 1.- Trabajo bajo control directo de personas de confianza. 2.- En ningún caso otorgarle trabajo independiente. B.- Deben firmar una declaración jurada ante el Jefe del Servicio o patrón, en que renuncia a cualquier actividad de tipo político, y su realización será causal para su inmediato despido"²3.

El "Monje Loco" no dudó en tomar medidas represivas contra cualquier atisbo de grupos organizados, prueba de ello fue que a fines de diciembre de 1973 se encarceló a una parte de los obreros contratados para la descarga del buque Tocopilla. De los 25 detenidos la mayoría de ellos eran rapanui, que lo fueron por exigir un aumento de "ciento cincuenta por ciento" del salario ${ }^{24}$. Del mismo modo, fueron enviados a

21 En Archivo Intendencia de Valparaíso.

22 En algunas conversaciones con personas rapanui sobre el tema constatamos que existe una diversidad de memorias sobre éste, siendo evidente el hecho de que es un periodo del cual no se desea hablar y es definido como "aquí no pasó nada".

23 En Archivo Gobernación Isla de Pascua (P1640011). Hay una constancia, del 14 de mayo de 1974, de la contratación, bajo esta modalidad, de 3 “exonerados” por la Empresa Longhi: Luis Enrique Salazar, Enrique Haoa Pakomio y Pedro Tuki Tepano (en Archivo de la Gobernación de Isla de Pascua (P1630992 y ss)).

24 Copiamos el listado enviado en un telegrama a la Intendencia de Valparaíso: "Raimundo Pérez Alvarado 27 años casado obrero agrícola sin filiación política; pascuenses solteros: Edmundo Pont Chávez 20 años obrero agrícola; Enrique Ika Ika 18 años sin oficio; Lorenzo Haoa Pakomio 27 años obrero agrícola; Eusebio León León 23 años pescador. Casados básicos: Federico Paté Tuki 28 años obrero agrícola; Esteban Pakarati 48 años carpintero; André Pate Tuki 26 años obrero agrícola; 
Santiago, a comienzos de enero de 1974, los hermanos Joel y Carlos Hucke Atán, así como Patricia Saavedra Lizama, para ser sometidos a la Justicia Naval, siendo acusados de pertenecer a un "movimiento separatista Chile-Pascua". Copiamos la carta de Joel Hucke fechada el 2 de octubre de 1974 donde denuncia lo arbitrario de la medida:

2/10 1974

Valparaíso.-

Al Señor Intendente de la Provincia

Presente.-

Muy señor, nuestro, el motivo de esta petición, es de ponerte en conocimientos con fecha 24, enero $1974^{25}$. El Servicio de Inteligencia Militar, nos trajeron, de la Isla de Pascua, por una falsa acusación del señor Gobernador don Omar Fuenzalida.

De que yo Andrés Joel Hucke, Carlos Hucke Atán y Patricia Zavedra (sic) L. pertenecimos de un Movimientos separatistas Chile y Pascua.

Con fecha, 28 enero 74 nos trajeron a la Fiscalía Naval, para interrogar sobre el caso.

El, abogado Fiscal, nos dejaron en libertad al comprobar que tal acusación es falsa.-

Pedimos a Ud. Que, nos mande de vueltas a la Isla de Pascua, con LAN Chile.

Esperando su pronta acogida a nuestra petición.

Andrés Joel Hucke A.

Av. Central-Pasaje 4 Poniente. 1329 José María Caro"26.

En febrero de 1974, el Gobernador impugnó la elección de Presidente y Vicepresidente de la Cooperativa (Enrique Haoa Pakomio) por desempeño político anterior al $11 \mathrm{de}$ septiembre de $1973^{27}$. Empero, la situación de Luis Pate Paoa ("Papa Kiko"), una figura emblemática del movimiento cultural rapanui, pone de manifiesto el cuidado político del "Monje Loco" en los asuntos internos de la Isla. El 8 de febrero de 1974 le envió una nota al Subsecretario de Educación (con copia al Subsecretario del Interior y al Intendente de Valparaíso) sobre la reducción horaria a que se vería afecto Papa Kiko en el Colegio, allí le solicita revertir esta medida, las razones son varias, una de ellas

Roberto Tepano Hito 23 años sin oficio; Enrique Haoa Pakomio 29 años obrero agrícola casado. Analfabetos: Salomón Teao Ika 50 años pescador. Todos sin filiación política. Victoriano Riroroko Atán 18 años soltero y Emilio Laharoa 16 años soltero ambos sin filiación política auxiliares de tierra de LAN que concurrieron a trabajar por atender avión no afectados responsabilidad. Raúl Teao Hay 23 básico, casado pescado por sospecha de ser instigador no contratado y afecto paro" (en Archivo de la Intendencia de Valparaíso, Caja 1973, N³34-335).

25 Un telegrama en la Gobernación de Pascua, del 25 de enero solicitaba la autorización a petición del Servicio de Inteligencia (en Archivo Gobernación Isla de Pascua, P1620285).

26 En Archivo de la Intendencia de Valparaíso, Gobierno Interior K. 241-255.

27 En Archivo Gobernación Isla de Pascua, P1640084. En la obra de Delsing se reproduce la versión de Joel sobre los motivos que llevaron a las autoridades a tomar tal medida (2015: 74). 
es que: "ha dado margen a muchos comentarios entre la población, en el sentido que los Continentales tratarían de destruirles sus costumbres y quitarles sus tradiciones":

Señor Subsecretario:

Esta Gobernación Departamental por informaciones extraoficiales ha sabido que se habrían efectuado algunos traslados de profesores de la Escuela $\mathrm{N}^{\circ} 1$ de esta localidad entre los cuales figuraría LUIS PATE PAOA, profesor de arte folklórico con dos horas semanales de clases. De ser efectiva esta medida, el Gobernador infrascrito puede manifestar a US. lo siguiente:

Dicho profesor, es un hombre de unos 50 años, casado obrero del fundo fiscal "Vaitea" en esta Isla, semi analfabeto, pero es la única persona que mantiene y está capacitado para enseñar las costumbres y folklore pascuense y lo hace con gran acierto, además se trata de una persona con una salud notablemente resentida, debido a la enfermedad de Hansen.

Cabría agregar que es un hombre natural de Isla de Pascua y que ha vivido solamente en la Isla, donde tiene todos sus familiares e intereses, además de ser una persona fundamental en la Isla para el desarrollo del Turismo y por lo cual es solicitado muy a menudo por grupos de turistas, tanto Nacionales como Extranjeros que visitan la Isla.

Por estas consideraciones, por estimar que el hecho de su cambio de residencia perjudicaría notoriamente a esta persona y a la Isla en general, es que me permito solicitar a US. si lo tiene a bien, examinar los antecedentes que dieron origen a esta medida y arbitrar las gestiones tendientes a reparar esta situación, que ha dado margen a muchos comentarios entre la población, en el sentido que los Continentales tratarían de destruirles sus costumbres y quitarles sus tradiciones.

Saluda atentamente a US.

Omar Fuenzalida

Mayor de Carabineros

GOBERNADOR $^{28}$

La "exoneración" fue la tónica contra los militantes de la UP, no obstante hubo represión, en la cual el más afectado resultó ser Víctor Acuña Vargas: "practicante y laboratorista" del Hospital de la Isla, Presidente del Partido Comunista, Regidor hasta el 11 de septiembre, miembro del ex CUP, Presidente de la Confederación de Trabajadores de Isla de Pascua, y según los términos del Gobernador: "activo dirigente laboral, peligroso". En enero de 2013 estuvimos con él en Rapa Nui, recibiendo su testimonio de las torturas sufridas en la cárcel de la Isla.

El 3 de agosto de 1974, Omar Fuenzalida, "Monje Loco", dejó el cargo de Gobernador, siendo reemplazado por el capitán de Carabineros Guiseppe Arru Domínguez. Desconocemos las razones de su salida, lo que está claro es que las medidas que propuso a ODEPLAN eran contrarias a la política que Roberto Kelly, presidente de la 
Comisión Nacional de Isla de Pascua, estaba impulsando desde que asumió el cargo como Ministro:

En consideración a que esta estructura [de Planificación], compuesta por la Comisión Nacional y el Consejo Departamental, han funcionado para el progreso de la Isla, es conveniente que siga en funciones para atender los múltiples programas, proyectos y problemas de Isla de Pascua. El Comité Coordinador deberá seguir asesorando al Consejo de Departamental para completar el cuadro de estructura de planificación [...] En consideración a la necesidad de integración del isleño a la vida nacional y que esta se produzca con absoluto respeto a sus costumbres y tradiciones, es importante su participación y colaboración en la planificación y desarrollo de Isla de Pascua ${ }^{29}$.

\title{
Anexo 1
}

\author{
REPÚBLICA DE CHILE \\ MINISTERIO DEL INTERIOR \\ GOBERNACIÓN ISLA DE PASCUA \\ MSC/apa.
}

\begin{abstract}
Progreso y necesidades, en carácter de MEMORIA de Actividades y Obras de los Servicios Públicos.
\end{abstract}

Hanga Roa, 11 junio de 1973.

\section{SEÑOR INTENDENTE:}

En conformidad a lo dispuesto en los artículos $16^{\circ}$ inciso $1^{\circ}, 26$ letra 1. y 42 letra b., de la Ley de Régimen Interior y a la Circular $N^{\circ} 58$ de 6 de septiembre de 1962 del Ministerio del Interior, cúmpleme la satisfacción de elevar a US. la Memoria de las Actividades y Obras desarrolladas por los diferentes organismos dependientes del Ejecutivo en el Departamento de la Isla de Pascua, durante el año 1972, así como también algunas de sus necesidades.

Esta Gobernación ha procurado hacer una síntesis o resumen del trabajo de cada Servicio, a fin de abreviar junto con entregar una visión de las tareas que han cumplido hasta ahora, de modo de que se pueda desde lejos visualizar el desarrollo de la Isla y grado en que se encuentra.

29 Oficio del 4 de octubre de 1973 al gobernador Omar Fuenzalida, con copia al Ministro del Interior, General Oscar Bonilla; al Subsecretario del Interior, Cdte. Enrique Montero Marck; al Intendente de Valparaíso, Contralmirante Adolfo Walbaum W., y al representante de Odeplan en Isla de Pascua, Mario Arévalo P. (en Archivo Gobernación Isla de Pascua, P1530947). 


\section{I.- OFICINA DEPARTAMENTAL DE OBRAS PÚBLICAS ISLA DE PASCUA.}

a.- Tiene a su cargo la realización de las obras más extensas e intensas de la Isla, tanto en materia de Vialidad como de trabajos Portuarios, Sanitarios y Labores Varias, que absorben toda su capacidad laboral y de maquinarias.

b.- La obra principal es el AEROPUERTO, sus faenas de prolongación y ensanche y loza es estacionamiento.

c.- En cuanto a Aeropuerto, debe destacarse la construcción ya del Edificio Terminal, la construcción de una bodega de $24 \mathrm{~m} 2$. para Entrega de Equipaje y Carga y la construcción de un local abierto de $147 \mathrm{~m} 2$. para ventas de Arte Pascuense, a base de eucaliptus, bambú y totora.

d.- Se menciona igualmente su constante misión de confección de parches de cemento asfáltico de diferentes dimensiones en la pista de aterrizaje y la imprimación de sectores agrietados con emulsión asfáltica.

\section{II.- DIRECCIÓN DE OBRAS SANITARIAS ISLA DE PASCUA.}

a.- Este Servicio ha logrado mantener un normal abastecimiento de agua dentro de relativas dificultades que se explicarían por la carencia de personal suficiente de trabajadores y de un vehículo para transporte de materiales.

b-. Durante el año 1972 se logró rectificar la salinidad de algunos pozos y semanalmente se hacen análisis bacteriológicos en el Laboratorio de Mataveri.

\section{III.- CORPORACIÓN DE FOMENTO DE LA PRODUCCIÓN-AGENCIA ISLA} DE PASCUA.

a.- Suministra a la población de Hanga Roa los servicios eléctricos suficientes para sus actuales necesidades, a través de una Planta Caterpillar y una Planta White, con sus respectivos grupos alternadores, quintuplicando su potencia, lo que por cierto ha demandado elevados costos materiales.

b.- Se han hecho extensiones de alta y baja tensión y montajes de subestaciones, en beneficio de ENTEL-CHILE, Hostería HONSA, LAN-CHILE y acoplamiento de servicios urbanos a 70 casas nuevas, además de un Grupo Alternador en el Fundo Vaitea.

c.- Hay proyectos de extensión de redes de cables para mejorar servicios como Aeronáutica, Carabineros y Corporación Forestal.

d.- En virtud de un convenio, CORFO ejerce tuición sobre el movimiento marítimo de la Isla, vigilando el complejo correspondiente, es decir, mantención y reparación de muelles y bodegas, balsas, pangas remolcadoras, lubricantes, repuestos, etc., así como la carga y descarga de cuatro barcos de Empremar y nueve barcos petroleros, aparte de cuatro barcos turísticos.

e.- Se instalaron tres cámaras de refrigeración, dos congeladoras y una nueva conservera, a fin de guardar los artículos perecibles de ECA, Cooperativa, proveedores de carne de equino e interesados particulares.

f.- CORFO posee una planta para la confección de tubos, codos, tees y piletas de alcantarilla, pero especialmente de BLOQUES para construcción, en número de 75.000 de $15 \times 20 \times 40$, lo que ha permitido agilizar la construcción. Por ejemplo la Hostería HONSA fué una realización de Corfo en su proyecto y construcción, basta traspasarla a HONSA. 


\section{IV.- CORFO. EMPRESA AGRÍCOLA CORFO ISLA DE PASCUA - SACOR. FUNDO VAITEA.}

a.- Ganado vacuno: de 198 cabezas en 1971 ahora existe un plantel de 397, mejorados con la presencia de 7 toros Hereford finos, destinados a cubrir 120 vacas y vaquillas de vientre. Se calcula que con un número mayor a 750 vacunos se daría el autoabastecimiento; se trabaja en este proyecto.

b.- Ganado ovino: la crianza está estabilizada en 25.000 unidades no obstante factores adversos como robos, ataques de perros, enfermedades (mosca azul) y un aumento en las ventas de este tipo de carne a la población.

En cuanto a robos se ha adoptado ya precauciones, así como en cuanto a perros. Hay consideradas otras medidas para mejorar la capacidad talajera (riego mecánico con bombas y la adquisición de 600 nuevos reproductores finos), ya que los machos actuales son viejos para el encaste.

c.- Huerto hortícola: por primera vez hay en producción un cultivo de hortalizas que satisface en parte importante la demanda de la población, que es mucha, pero esta producción está condicionada a las caídas pluviométricas por carecerse de riego mecánico y bombas, a pesar de existir excelentes napas a 80 y 120 metros. La superficie de este huerto es de tres hectáreas.

d.- Huerto frutal: se plantaron dos hectáreas con citrus, paltas y chirimoyos y otras variedades tropicales que en el plazo de dos años darán plena producción económica. Las superficies de ambos huertos no pueden aumentarse por ahora dado el factor limitante del agua, que es agudo en los meses de noviembre a marzo.

El huerto agrícola ha producido repollos, lechugas, achicorias, cilantros, pimentaciones, acelgas, espinacas, ajíes, cebollas, tomates y zanahorias en cantidad estimable. En menor número coliflores, apio, rabanitos, perejil, berenjenas, sandías y zapallos.

e.- Caída pluviométrica de los años 1971 y 1972: En 1971 cayeron 1.149,1 mm. y en $19721.437,8 \mathrm{~mm}$. estableciéndose una diferencia de $288.7 \mathrm{~mm}$. de agua caída, que, en climatología, es una caída que necesita regularizarse mecánicamente.

f. Sede Social: está en construcción y faltándole solamente las puertas y ventanas, piso, instalación eléctrica y baños, un local para sede social, en el pueblo mismo, de los trabajadores del Fundo Vaitea, la cual estará dotada de biblioteca, tocadiscos, mesas de ping-pong, damas, ludos, ajedrez, etc.

g.- Programa forestal: para un plan de forestación se han apotrerado con alambradas, 600 hectáreas en distintos sectores del Fundo, plantación que corresponde ejecutar a la nueva Corporación de Reforestación o CONAF. El cierre de estas 600 hectáreas quedó terminado en abril de 1972, entregándolas el Fundo al Sr. Adán Burgos primero y enseguida al Sr. Roberto Ramis.

h.- Protección arqueológica: de mutuo propio CORFO Vaitea hizo cercar totalmente el "Rano Raraku", como medida de protección arqueológica y para defender el cerro y los moais de los daños que causan animales, vehículos y gentes.

i.- Comité de Administración: el Administrador y el Fundo cuentan con un Comité de Administración, formado por trabajadores, que estudian y debaten los programas de trabajo en bien de la comunidad. En este sentido se registran mejoras en el suministro de agua potable a las viviendas e instalaciones del predio, cambios de cañerías y la puesta en marcha de un grupo alternador M.A.N. de 40 H.P. y corriente de 220 volts. 


\section{V.- EMPRESA NACIONAL DE TELECOMUNICACIONES S.A. (ENTEL-CHLE)}

a.- Se construyó e instaló una Radio- Estación transmisora y Receptora de ondas cortas en "Pu 'Ohiro" en el interior del Fundo Fiscal Vaitea.

b.- Se construyó una Oficina Terminal en el centro de la ciudad, con sala de espera y dos amplias cabinas telefónicas, además de Mesón y Pupitre para la Operadora, lo que significó un notable mejoramiento de las anteriores condiciones. Falta ampliar los canales y la red interna.

VI.- CORPORACIÓN NACIONAL FORESTAL (CONAF)- PARQUE NACIONAL DE TURISMO.

a.- Organismo nuevo que marginó al SAG de sus funciones forestales y asumiendo la Administración del Parque Nacional de Turismo de la Isla, cambio que se produjo y concretó en la primera mitad del año 1972.

b.- Colaboró al SAG en la campaña o erradicación de la mosca de la fruta "daucus tryoni".

c.- Ha asignado a sus tareas de la tierra y el árbol una "función social" y con este criterio expresa que ha contribuido a la ornamentación de Servicios tales como Carabineros, Honsa, Corfo mediante plantas y con rollizos y estacas de eucaliptus para construcciones y cercos de SAG, INDAP, Proyecto Mataveri, Vaitea y construcciones particulares.

d.- Produjo veinte mil plantas en sembradero (20.000 bolsitas) para el control de la erosión en el Cerro Orito, además de plantaciones ornamentales en el Parque.

e.- Hay un intenso programa para 1973 de cercos, delimitaciones, quinchas de erosión, siembra directa de forestación utilitaria y producción de 100.000 plantas en sembradero.

VII.- MINISTERIO DE TIERRAS Y COLONIZACIÓN-OFICINA DE TIERRAS Y B. NACIONALES.

a.- Realizó una labor normal y corriente de levantamientos topográficos y división de parcelas en el área rural y de subdivisión de sitios e hijuelas en el sector urbano, aparte del trabajo de gabinete de planos individuales, de sitios y parcelas.

b.- Dispone de vehículo desde mediados de 1972.

c.- Subsiste el problema del Plano Regulador, aprobado pero cuestionado al mismo tiempo por la Municipalidad, la que expresa su desaprobación no aprobando el Plano de Loteo. (Se dictó ley que permite prescindir de esta aprobación Municipal). VIII.-BANCO DEL ESTADO DE CHILE - SUCURSAL ISLA DE PASCUA.

a.- Cumple sus actividades conforme a su reglamentación y en la misma forma y horario del Continente.

b.- Se creo una Caja-Auxiliar de Cambios Internacionales en el Aeropuerto de "Mataveri”, para atender los pasajeros de los vuelos de los días jueves y sábado. Esta caja tiene estrecha relación con la aplicación y observancia de la Ley de Cambios, que no operaba en la Isla y que se hizo aplicar desde febrero de 1972, previas las advertencias e instrucciones que se dieron a la población y comercio establecido. c.- Ahorros: el balance de 1972 arrojó un total aproximado de $\mathrm{E}^{\circ}$ 16.000.000.- saldo conformado principalmente por Ahorros y Cuentas Corrientes Comerciales y Cuenta Única Fiscal Subsidiaria. 
d.- Créditos: se han otorgado a pequeños agricultores, industriales, para reparaciones de viviendas y compra de menaje, sin indicarse monto.

e.- Divisas: el Banco controló un monto aproximado de US\$ 40.000.- americanos en billetes y traveller cheques, más otras compras menores de diferentes monedas. f.- Nuevo local de Oficina: en mayo de 1972 la Sucursal se instaló en su nueva oficina, ofreciendo amplitud y mayores comodidades al público y Planta de personal, constituida por 5 funcionarios.

IX.- CARABINEROS DE CHILE - 9 $9^{\text {a }}$ COMISARIA "ISLA DE PASCUA".

a.- Las casas-habitaciones del personal fueron mejoradas en sus instalaciones internas, se reforestó el recinto con árboles y plantas. Se instaló una bomba bencinera capacidad 12.000 litros y se construyó una nueva casa- habitación de personal a contrata.

b.- Se necesita un nuevo cuartel, de material sólido y nueva Sección Cárcel. Además el cambio de los vehículos motorizados.

X.- ARMADA DE CHILE - CAPITANÍA DE PUERTO ISLA DE PASCUA.

a.- Este servicio se abstuvo de entregar datos de progreso y necesidades, por corresponder, asegura, a las Reparticiones superiores.

b.- Se registraron diez embarcaciones que recalaron en la Isla, entre naves de pasajeros, buques científicos, motonaves chilenas con mercaderías y yates de navegantes solitarios. Los principales fueron el "SS. FRANCE", el "Presidente Wilson", el "James Gillíes" y "Dimitri Mendeleyev", norteamericanos y soviéticos estos últimos.

XI.- CANTÓN DE RECLUTAMIENTO N 12 "HANGA ROA".

a.- Labor y actividades normales, de acuerdo a la población de la Isla. Hay opiniones responsables de que por su mínima cuantía, esta labor podría anexarse a otro Servicio, economizando el Estado un funcionario, más la oficina y la casa que están en proyecto. No se desconoce por la Gobernación el sentido de patriotismo que infunde este Servicio.

XII.- LAN-CHILE - AGENCIA COMERCIAL ISLA DE PASCUA.

a.- Durante 1972 LAN tuvo una operación normal de una frecuencia semanal con el Vuelo 131 entre Santiago y Papeete con tránsito por Isla de Pascua todos los jueves. Durante el mismo año 1972 y de regreso de Papeete se originó el Vuelo 130 con destino a Santiago con tránsito en Isla de Pascua todos los sábados.

b.- El movimiento de pasajeros, carga y postal, en conjunto, fue el siguiente:

Pasajeros destino Santiago y Papeete 3.705 que produjeron un ingreso de $\mathrm{E}^{\circ}$ 3.422.209.56 y US\$ 3.28340

Carga con destino a Santiago y Papeete 83.092 kilos con un ingreso de $\mathrm{E}^{\circ} 800,182.40$ y US\$ 1.168.50.

Pasajeros que arribaron a la Isla:

Carga llegada a la Isla:

328.022. kilos

Correo postal llegado:

807. kilos

Correo postal salido:

375. Kilos

c.- No es aventurado expresar que LAN tiene amplias perspectivas en el desarrollo de la Isla, a base del aumento de sus frecuencias de Vuelos, lo que está ligado a la 
modernización y extensión del Aeropuerto y la participación correlativa y coordinada de otros organismos tales como ODEPLAN, DITUR, HONSA, INDAP y otros relacionados con la vivienda, explotación pesquera y agrícola, etc.

XIII.- CORREOS Y TELÉGRAFOS - AGENCIA POSTAL ISLA DE PASCUA.

a.- Este servicio funciona adyacente a la Oficina de la Gobernación Departamental de la Isla de Pascua, a cargo de un Agente Postal.

b.- Durante 1972 su movimiento de correspondencia aérea y marítima fue de 32.552 piezas postales. Mantiene en la caja de fondo de cargo un presupuesto de $\mathrm{E}^{\circ} 10.000$.c.- Se necesita un local apropiado para Oficina, asimismo dotarlo de algún elemento motorizado por la distancia existente (4 kmts.) entre la Oficina y el Aeropuerto para el despacho y recepción de la bolsa de correspondencia.

d.- Requiere de la impresión de sellos postales con motivos autóctonos.

e.- Considerar el sueldo para el funcionario a servir en la Agencia, por cuanto en la actualidad percibe una renta de $\mathrm{E}^{\mathrm{o}} 1.300$.-

f.- Dotar a la Oficina de elementos indispensables tales como: máquina de escribir, tampones, útiles de escritorio, útiles de aseo, goma de pegar, insecticidas, etc.

XIV.- SERVICIO AGRÍCOLA Y GANADERO (SAG).

a.- Desarrolló una sostenida acción de fumigación en contra de las pestes que asolan la agricultura pascuense, destacando su campaña contra la mosca australiana (dacus tryoni). El Servicio contó con la asistencia de técnicos nacionales y extranjeros y la participación durante varios meses de dos aviones fumigadores. Su trabajo es constante y de vigilancia y, aparte de estar reduciendo un brote de chamico que es una planta maleza dañina tiene en programación en 1973 una campaña de desratización masiva y total, en coordinación con el Servicio Nacional de Salud de Santiago. En la acción contra el "chamico" está participando igualmente Corfo-Agrícola, a través del Fundo "Vaitea".

\section{XV.- HOTELERA NACIONAL S.A., HONSA - HOTEL "HANGA ROA".}

a.- La Hostería ha estado cumpliendo satisfactoriamente su trabajo específico de recepción y atención de huéspedes y turistas extranjeros y nacionales, con su capacidad de 60 habitaciones dobles, cuya demanda ha ido creciendo a través de los meses de 1972 y primeros de 1973, en forma que se hará insuficiente una vez programados a firme una mayor cantidad de Vuelos de LAN por semana.

b.- En la próxima Memoria deberá contarse ya con datos numéricos de pasajeros y sus respectivos ingresos en moneda nacional o divisas, como corresponde a un trabajo de esta índole para poder en un futuro evaluar y comparar su movimiento anual.

c.- Durante 1972 se registran mejoras importantes en sus instalaciones tales como la construcción de una cámara de inspección profunda en el sistema de alcantarillado, la instalación de un "bypass" en el sistema de aducción de agua potable para suplir una insuficiente presión y por último la colocación de un aditamento tipo "Venturi" para mejorar el equilibrio de presiones entre los ramales principales para el suministro de agua a los servicios.

XVI.- EMPRESA DE COMERCIO AGRÍCOLA - AGENCIA ISLA DE PASCUA. a.- La Agencia ECA local durante 1972, cumplió en general con su misión de proveer a la población de los abastecimientos alimenticios que transporta a través de Empremar, semestralmente y de Lan, semanalmente, en lo que se refiere a 
ciertas cantidades de alimentos perecibles como pollos y carnes. Es necesario dejar constancia que no obstante ser suficientes las cantidades dispuestas, hubo entorpecimientos durante parte de 1972 a causa de retraso en Empremar y de que cierta cantidad de pobladores adquirió mercaderías con distinto criterio al de atender a sus propias y reales necesidades. Este grave hecho se subsanó y está en vigencia un sistema equitativo de venta y entrega a base de grupos familiares individualizados que impide el abuso o el dualismo, que ha resultado favorable en todo sentido.

b.- Debe señalarse empero que, en casos especiales, el Gobierno ha enviado mercaderías por medio del Hércules de FACH, el buque "Lago General Carrera" o bien aumentando sus envíos a través de los arribos semanales de Lan.

c.- En cuanto a avances es preciso hacer mención de la instalación del Almacén de Ventas y de las propias oficinas en el centro de la población y el aumento de los rubros de vestuario y materiales de construcción.

Debe tenerse presente que el clima y humedad no hacen recomendable el abarrotamiento de las bodegas, ya que peligra la conservación de los alimentos por períodos superiores a cuatro, cinco o seis meses. Esta dificultad hace imperativa la normalización de los viajes de Empremar.

d.- Se espera en una próxima Memoria contar con datos numéricos y determinación de mercaderías, costos e ingresos.

\section{NOTA:}

a.- Se adjuntan cuadros informativos que se estiman útiles para un posterior estudio de la Isla, referentes a: 1) Comparación de trabajadores continentales con pascuenses 2) Empresas de transportes y particulares que ejercen el comercio de turismo 3) Dueños y detalles de hospederías y 4) Continentales que se han establecido en el Departamento de Isla de Pascua. 
CUADRO PARA COMPARAR ESPECIALMENTE NUMERO DE TRABAJADORES CONTINENTALES CON PASCUENSES (a febrero 1973)

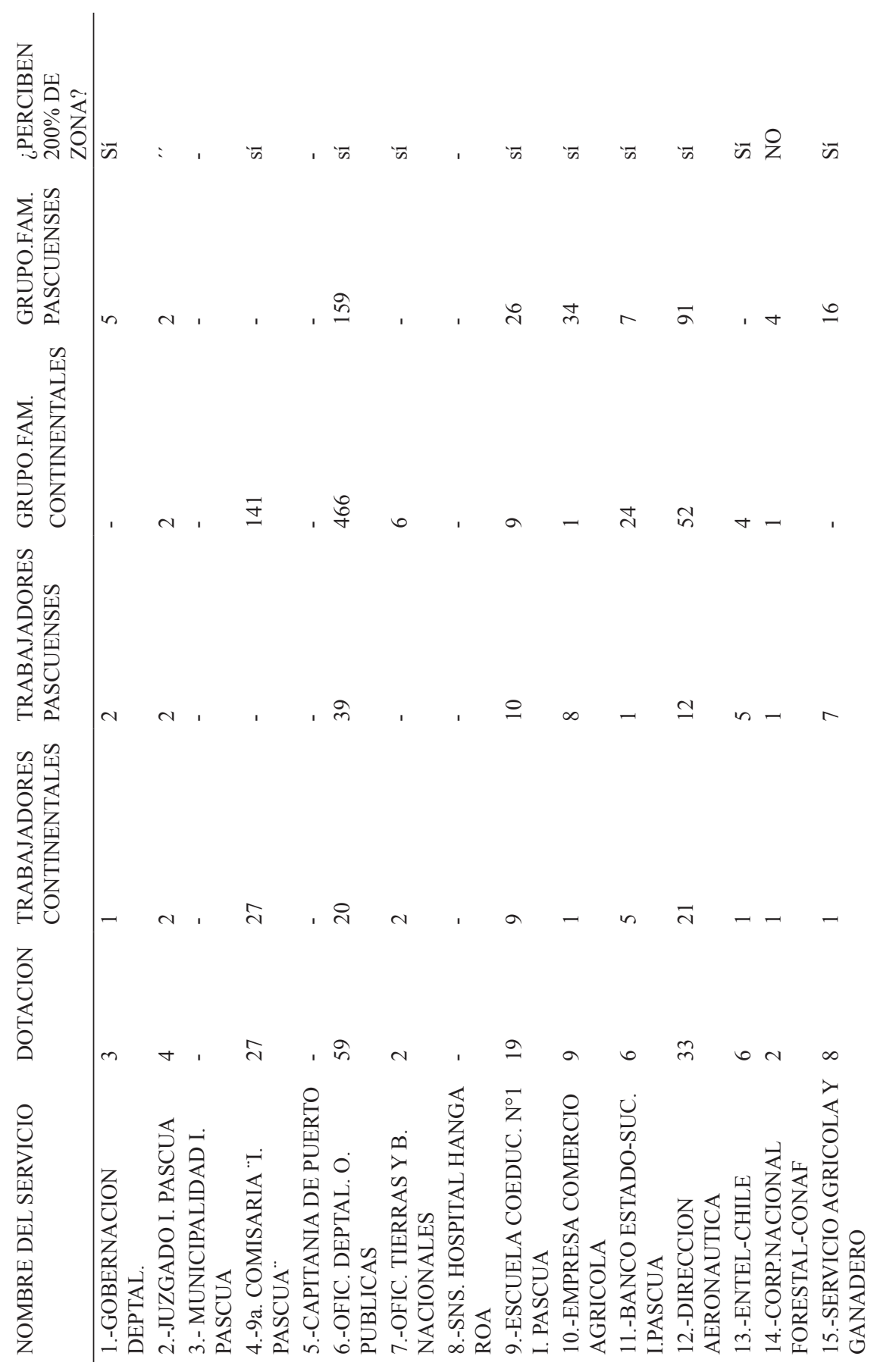




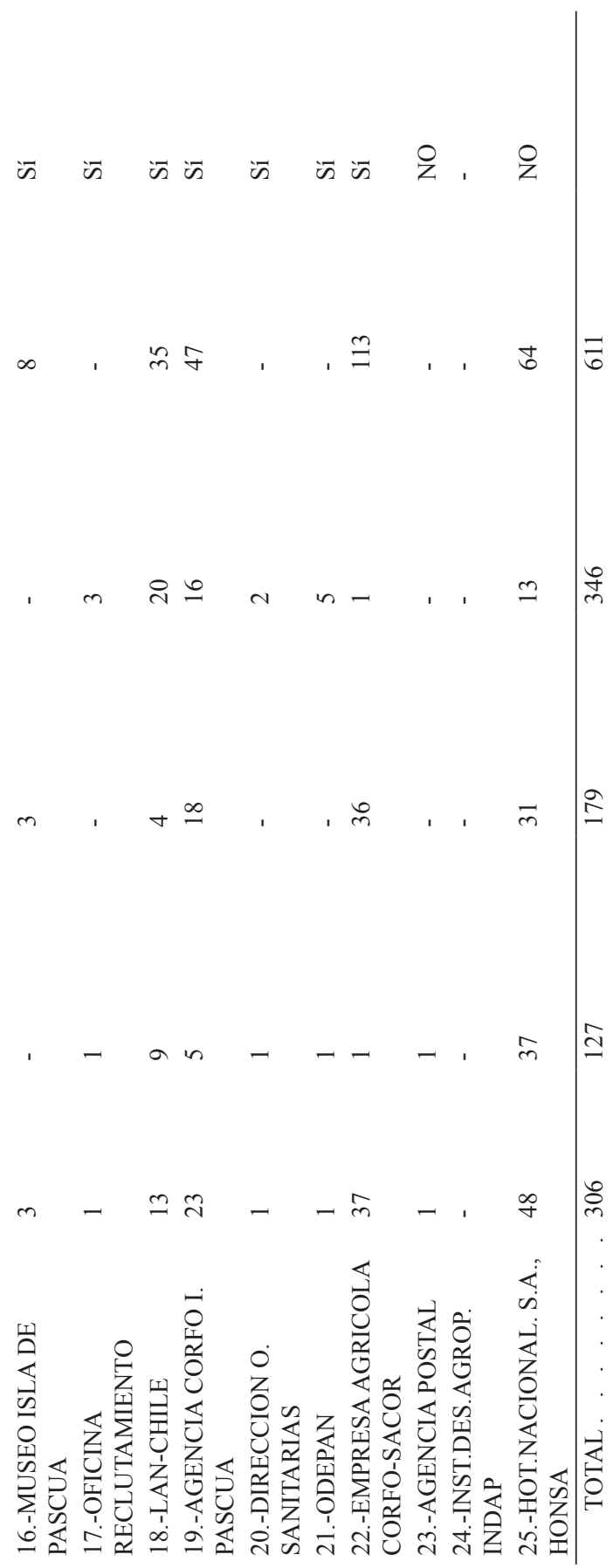


EMPRESAS DE TRANSPORTES Y PARTICULARES QUE EJERCEN EL COMERCIO DE TURISMO ( a febrero 1973 )

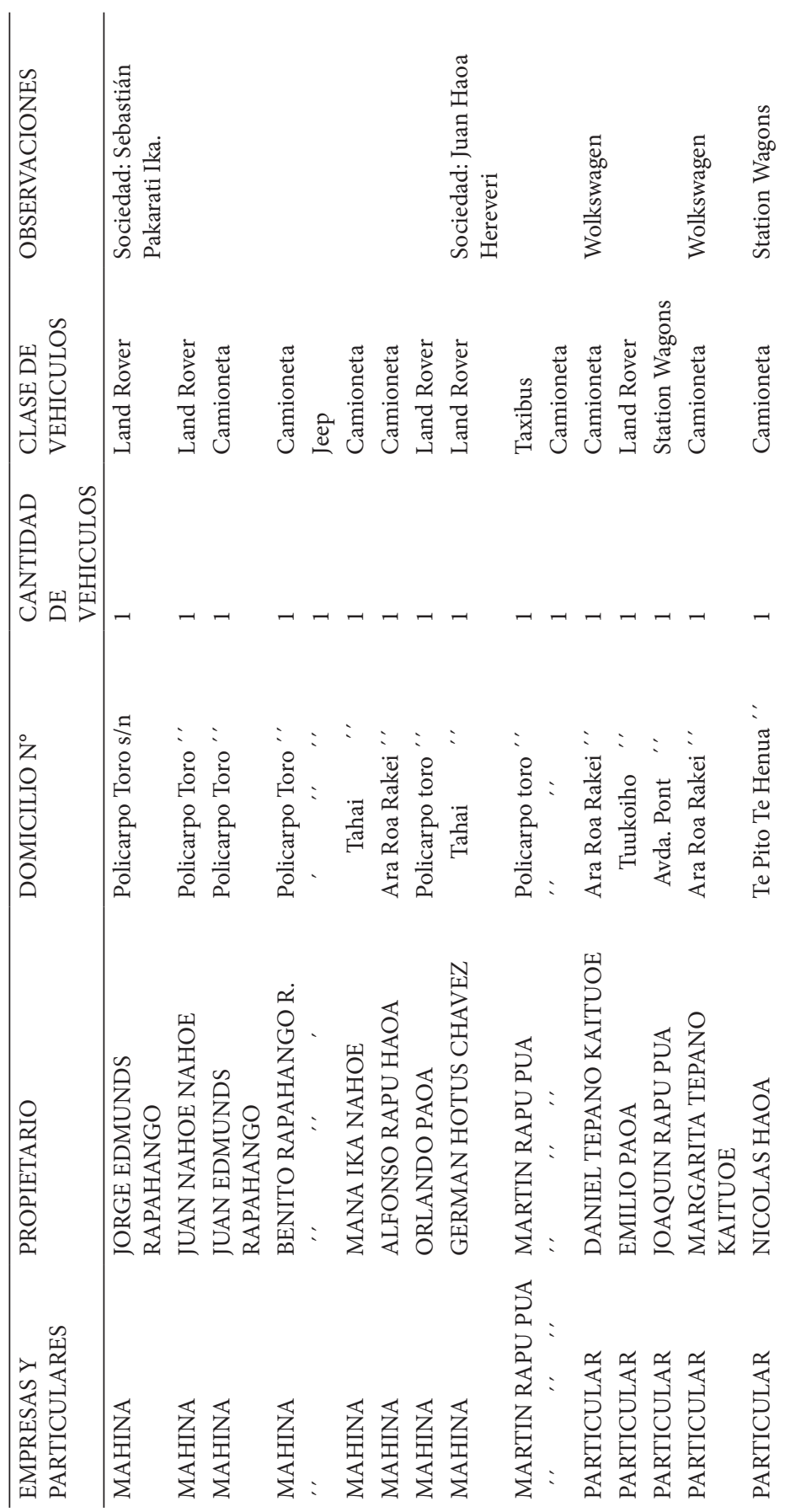




\section{DUEÑOS Y DETALLES DE HOSPEDERÍAS ( a febrero 1973 )}

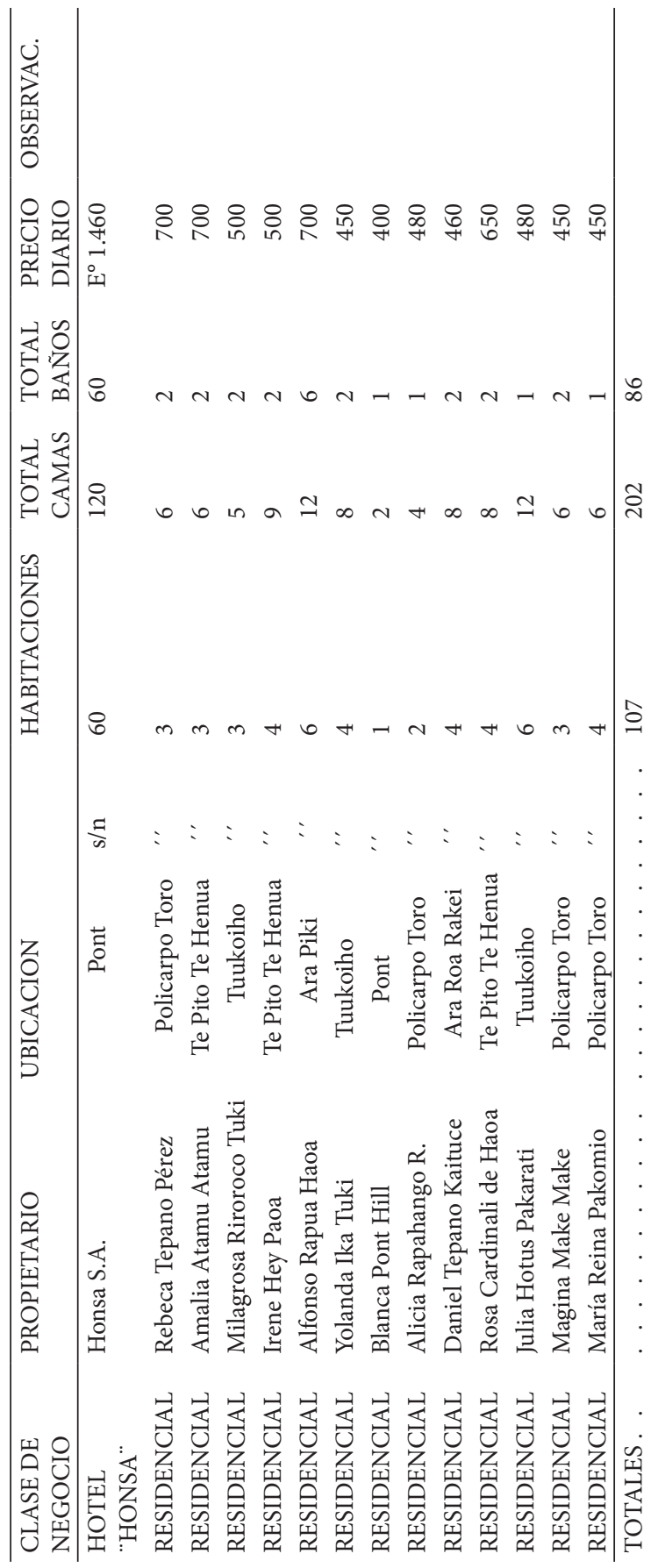


CONTINENTALES Y EXTRANJEROS QUE SE HAN ESTABLECIDO

EN EL DEPTO. ISLA DE PASCUA ( a febrero 1973 )

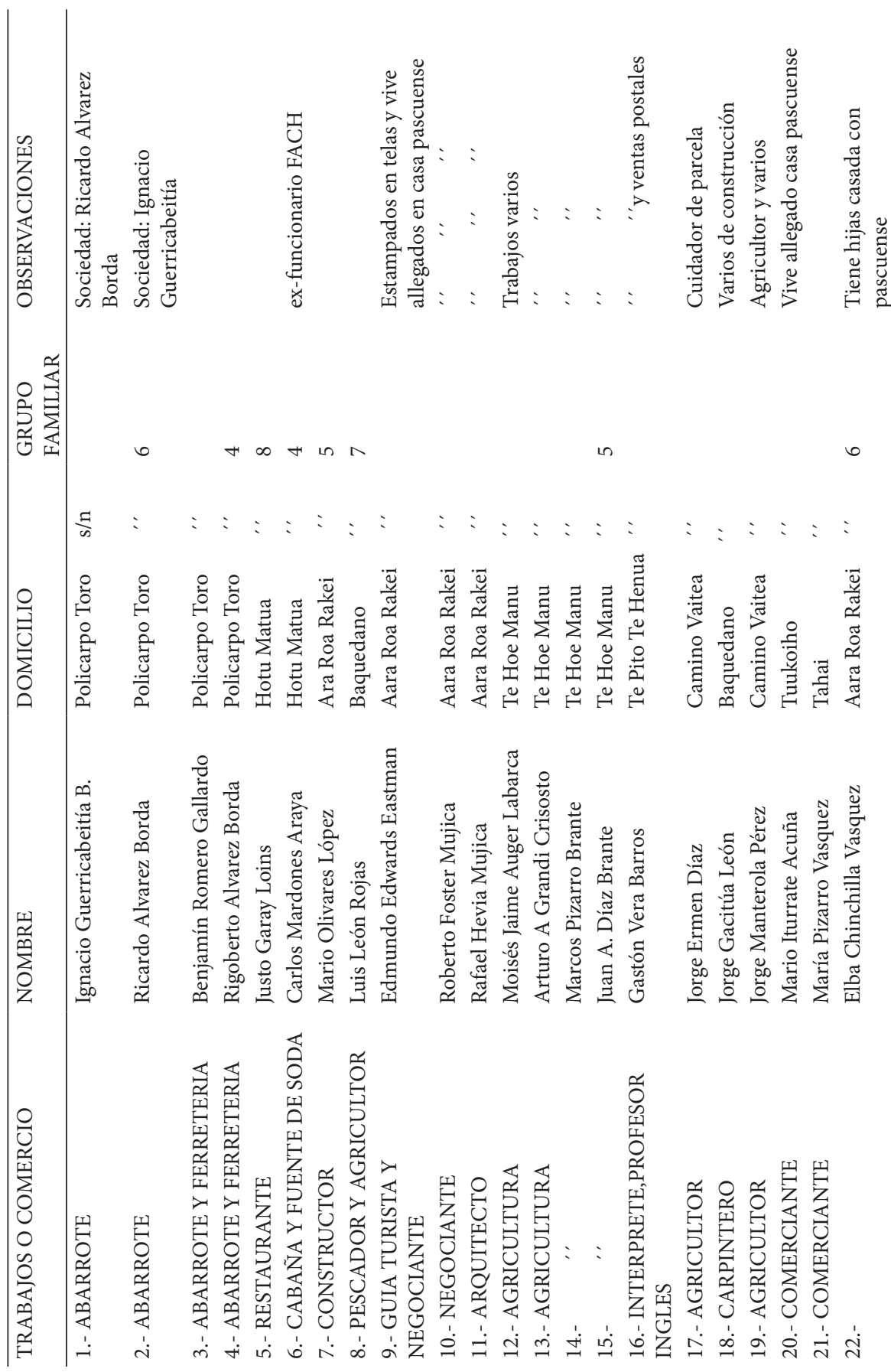




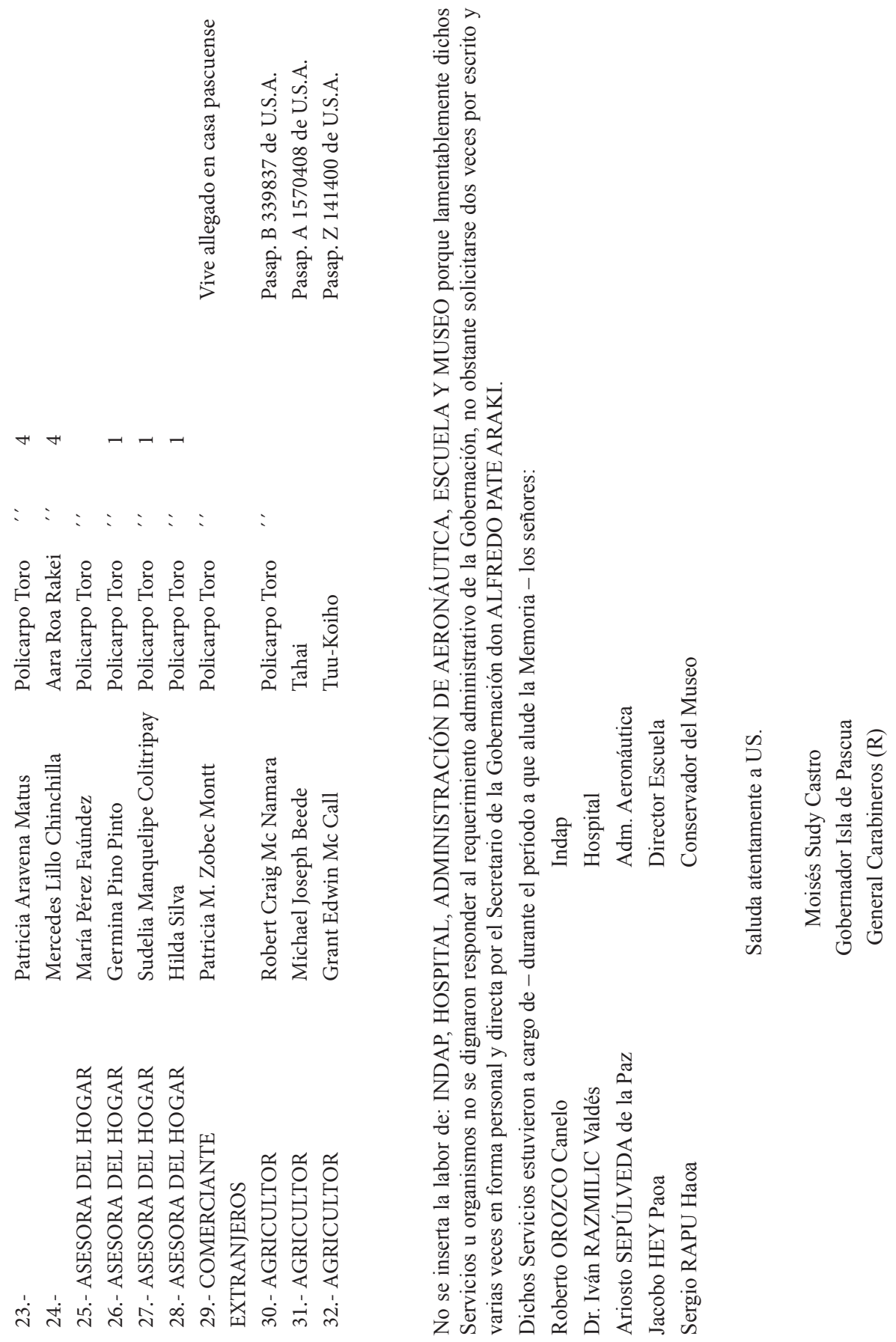




\author{
AL SEÑOR \\ INTENDENTE DE LA PROVINCIA DE \\ V A L P A R A I S O/
}

Anexo II

\title{
RESERVADO
}

HANGA-ROA, 19 OCTUBRE 73.-

Al Sr. Coronel

DON ROBERTO KELLY VÁSQUEZ

Director de la Comisión Nacional

De Desarrollo de Isla de Pascua.

SANTIAGO.

En atención a la conversación telefónica del día martes 16 del actual y con la confianza que se deben tener los miembros de Instituciones Armadas, me permito informar las experiencias del infrascrito en el lapso de un año y siete meses de permanencia en Isla de Pascua, en relación a las actividades administrativas del Departamento. -

Para su información, soy Mayor de Carabineros OMAR JORGE FUENZALIDA

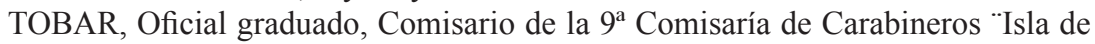
Pascua", 42 años de edad con 23 años de servicios en la Institución, servicios en: Santiago 3 años; Osorno 2 años; Traiguén 4 años; Lonquimay 5 años; Victoria 2 años; Lota Alto 4 años; nuevamente Santiago 2 años e Isla de Pascua. Casado con 3 hijos, domiciliado en Recinto Policial de "Mataveri". -

Como Comisario de Carabineros me corresponde participar en el Comité Coordinador de Isla de Pascua, desde abril de 1972, estando en esa fecha compuesto por 23 servicios. Actualmente son 26. -

Nuestra labor no tiene ninguna significación, salvo el de aceptar planes y proposiciones del Gobierno, previamente preparados por el grupo de Jefes de Servicios y del Gobernador, en reuniones previas del CUP, lo que se comprobó en numerosas ocasiones y estando éstos en gran mayoría en dicho Comité, se aprobaba solamente lo ya acordado con anterioridad. -

El Comité en la actualidad está compuesto por 26 miembros: 19 marxistas; 4 contrarios a la ex-UP y 3 apolíticos (Comisario de Carabineros, Capitán de Puerto y Jefe de Aeronáutica). Se hace presente que la única modificación que ha sufrido la composición de éste Comité ha sido la del cambio del Gobernador por el infrascrito, lo que deja las cosas en una misma proporción. -

Por otra parte, éste Comité Coordinador solamente podía intercambiar opiniones entre los Jefes de Servicios sin poder hacer valer sus apreciaciones sobre el Comité de Desarrollo, integrado en su totalidad por pascuenses. Sólo servía para adecuar las decisiones de éste último. - 
El Consejo Departamental de Desarrollo de Isla de Pascua, el cual conoció personalmente el infrascrito por haberlo presidido durante una subrogación del Gobernador anterior, en 1972, pudo apreciar que lo componen 19 personas elegidas por la Gobernación Departamental en forma irregular y arreglada, por cuanto aparecen representantes de Juntas de Vecinos y Centros de Madres que no existen en la realidad, salvo en algunos informes elevados al Ministerio del interior y Odeplan; otros han sido elegidos por su clara tendencia izquierdistas, tales como los representantes obreros Urbanos y Rurales. -

Fuera de algunos capacitados de tendencias marxistas la mayoría son simples acompañantes que ocupan un asiento y no aportan absolutamente nada al desarrollo local, por el contrario entraban las reuniones al discutir necedades y darle gran importancia a circunstancias nimias.

Hay que entender que se debe a la poca capacidad intelectual y preparación de estos representantes isleños que son carentes de valores, manejables e interesados por lo material y hábilmente conducidos por los politiqueros.

En resumen el infrascrito estima que antes de dar mayor representación y poder a pascuenses, estos deben ser educados e instruidos para lo cual falta mucho por hacer. Incluso los más preparados pascuenses tienen dificultades para entender lo que leen con mayor razón los obreros y representantes que aparecen como componentes de seudos centros de madres y juntas de vecinos.

En cuanto a la Comisión de Desarrollo de Isla de Pascua, estimo que fue dirigida en forma totalmente politizada por los señores Sergio Inzunza, Lautaro Ojeda, Gonzalo Martner y Oscar Santelices; y en general está constituida por muchas personas que incluso no conocen la Isla y menos su realidad, lo que estudian son informes hábilmente preparados por personas interesadas, que no reflejan las condiciones existentes en la Isla por ir tras la busca de adeptos políticos y un paternalismo que lleva al pascuense a pensar que están sólo para recibir todo del fisco y no aportan nada en beneficio local y menos del país. Muchos otros buscan el lucro personal mediante comisiones frecuentes a Pascua que les reporta ingresos considerables ya que pueden disponer de los viáticos y sobresueldos en el continente con costo muy inferiores a los existentes en la localidad.

Al crearse otros dos organismos como son: el Instituto Cultural de Isla de Pascua y el Instituto Corfo de Isla de Pascua aumenta aun más la maraña de tramitaciones para realizar cualquier labor y diluyen las responsabilidades y coartan las ideas de trabajo de los funcionarios con iniciativas.

El Instituto Corfo de Isla de Pascua tal como esta concebido reportaría gran adelanto a la Isla pero tendrían que desaparecer otros organismos inoperantes y paralelos como el Consejo de Desarrollo y Consejo Coordinador.

Debe existir un organismo, que puede ser la "Comisión Nacional de Desarrollo de Isla de Pascua" debidamente reestructurado, disminuyendo el número de componentes y ampliándole sus atribuciones para dirigir el Instituto Corfo de Isla de Pascua y señalar orientación a los servicios que no serían absorbidos por este Instituto. Para mayor abundamiento puede decir que el Instituto Corfo tendría que absorber el SAG, CONAF, CORFO, CORFO-VAITEA, INDAP, MOPT, HONSA, TURISMO y ENAF. 
Debe modificarse el decreto $\mathrm{N}^{\circ} 1.139$ de 10 de agosto de 1971 en lo ya descrito Comisión Nacional, Comité de Desarrollo y Comité Asesor de Isla de Pascua. Modificar en especial el Art. $5^{\circ}$ que lleva al control absoluto de los funcionarios por parte de los politiqueros en gobierno de civiles, siendo un arma poderosa para los buscadores de votos. Llegan solo funcionarios incondicionales a trabajar políticamente y contando con el apoyo de Santiago se les ve realizar acciones reñidas con la sobriedad y honradez.

En la actualidad es necesidad que los servicios principales tales como Obras Públicas (Mopt) y Corfo debieran tener Jefes Técnicos de categoría, ingenieros con permanencia en la Isla para poder aquilatar, ordenar, disponer y solucionar las innumerables dificultades causadas por el aislamiento, falta de transporte y medios de comunicación más expeditos, pues hay obras que se paralizan por falta de una autorización o de un repuesto, de máquina o vehículos que se destruyen al quedar paralizados por falta de repuestos que no hay en existencia en las bodegas de los Servicios de la Isla, aunque se tiene como práctica común el de facilitarlos entre ellos, como dato ilustrativo es el caso de una serie de camiones que quedaron paralizados y se destruyeron por la acción de la corrosión, solo por falta de neumáticos, otros, un Station Wagons de la Gobernación, paralizado por falta de un eje cardan y actualmente semi destruido por la acción del ambiente húmedo y salino son estas situaciones las que deben obviarse mediante planificación especial para adquisiciones de Isla de Pascua a cargo de Jefes de mayor jerarquía y atribuciones.

Los simples informes no bastan para apreciar la situación local, recién al año de permanencia se puede captar la idiosincrasia del pascuense y los empleados menores solo cumplen las órdenes y esperan la visita de los Jefes para realizar las obras en ejecución.

Otro punto de gran importancia es la falta de seguridad en los transportes, es decir, Odeplan toma la reserva de carga y despacho del barco que viaja a Isla de Pascua pero en la ingrata realidad que de los cuatro viajes que deben efectuarse en el año se realizan dos y esos con grandes dificultades y atrasos hasta de cinco meses a la fecha anunciada para el zarpe y llegando en las peores épocas del año y por la larga permanencia en la descarga han regresado sin recibir gran parte de la carga local.

Esta política de atrasar el barco ya hizo perder la confianza de los usuarios quienes hacen la reserva de carga pero no las llevan al puerto porque están seguros que el zarpe no será en la fecha anunciada por Odeplan y no las dejan en el muelle sujetos a la inclemencia del tiempo y de lo que es peor al pillaje de la gente que labora en el puerto y cuando realmente sale la Motonave muchos no tienen su carga preparada o llegan en el último momento.

También el lapso de llegada a la Isla entre barco y barco distorsiona el precio de las mercaderías, ya que debe recurrirse al flete aéreo que es en este momento de $\mathrm{E}^{\circ}$ 46 por kilo de comestible y de $\mathrm{E}^{\circ} 112$ para otras mercaderías máxime que se debe devolver al continente los envases vacíos y la poca capacidad de carga del avión y pasado un tiempo mercaderías llegadas en el barco la hacen aparecer como pagando flete aéreo.

Otro aspecto es el marcado y visible espíritu de los chilenos que viven en el continente a tratar en forma paternista (sic) y conmiserativa a los nativos pascuenses en circunstancias que éstos son totalmente diferentes a la creencia de que son gente 
pobre y explotados, tal vez lo halla sido tiempo atrás, pero la realidad es otra. El pascuense es económicamente poderoso, pese a su bajo nivel de vida, no le atraen las comodidades y por tal razón sus casas son de aspecto descuidado e incómodas, prefieren mal vivir antes de efectuar gastos en inmuebles o bienes de capital. Son corrientes los pascuenses con cuentas bancarias en monedas duras, en el extranjero como también tienen bienes en Tahiti, América y Europa.

El pascuense no se considera chileno, sino polinésico y en especial pascuense y aspira a que "su" isla sea un fideicomiso de las Naciones Unidas o de Estados Unidos de N.A. y se han detectado diversos movimientos en este sentido en los años 1964, 1969 y últimamente en 1972, hechos conocidos por el servicio de Inteligencia de la Armada, según informe del Capitán de Puerto Local.

Al no ser posible el fideicomiso, aspiran a formar parte de la Confederación Polinésica, como estado semi-independiente con Capital Federal en Tahiti.

Esperan la oportunidad de ocupar puestos claves y tener la administración de la isla, para alcanzar su objetivo, por tal razón crean el mito de la persecución del continental hacia ellos, lo cual es todo lo contrario y lo peor es que son apoyados por las medidas gubernamentales, en especial las segregacionistas tales como:

a.- Prohibición de ocupar cargos y trabajos, por continentales, habiendo pascuenses que puedan ejecutar esas labores, aunque sean de inferior calidad o rendimiento.

b.- Preferencia para los cargos a pascuenses, luego los matrimonios mixtos y en último lugar los continentales.

c.- Derecho exclusivo de ocupar terrenos en la isla, aduciendo su propiedad, olvidando que el pueblo chileno la adquirió legalmente pagando por ella y que sólo había 56 (sic) pascuenses moribundos cuando el Capitán Policarpo Toro tomó posesión de Isla de Pascua, en 1888.

d.- El proyecto de Ley para Isla de Pascua mantiene y aumenta este tipo de medidas segregacionistas.

e.- Prohibición del avecindamiento de chilenos continentales que puedan trabajar y entrar en competencia en sus monopolios de residenciales, empresas de turismo, transportes, agricultura y pesca.

f.- Persecución del continental que trata de establecerse en trabajos propios, salvo que se emplee como obrero de los pascuenses, a los cuales explotan y no les pagan, quedando luego abandonados e incapacitados de regresar al continente por el alto costo de los pasajes.

En la actualidad, la gran mayoría de los chilenos continentales son empleados públicos unos pocos casados con pascuenses y un solo matrimonio continental que trabaja como mediero con pascuense.

En cuanto a los Servicios Públicos existentes, pueden distinguirse:

a).- Servicios inoperantes: 1.) INDAP; se elevó su número de Un empleado a Tres; uno para dirigir la Cooperativa Multiactiva, otro para instalar una pequeña industria conservera en construcción y el tercero para organizar la pesca artesanal, ninguna de las tres áreas presentan un progreso pese a llevar tres y dos años respectivamente de labor. La Cooperativa es rudimentaria con la conservera se trata de justificar 2 años de grandes gastos y pago de sueldos, teniéndose conocimiento que una similar 
es mantenida con menores gastos y personal. En cuanto a la organización de los pescadores, es insignificante y poco productivo el apoyo que les han dado. -

b).- Servicios que fueron divididos aumentando personal sin aumentar la eficacia: SAG. primitivamente era 1 Jefe y 6 obreros. Actualmente SAG tiene 1 Jefe, 6 obreros, además de CONAF, con 1 Jefe y 6 obreros. -

CORFO; se dividió en Corfo y Sacor. -

MOPT; se dividió en Mopt y proyecto Mataveri. -

c).- Servicios con aumento de Personal: HONSA, Hotel Hanga-Roa. Tiene actualmente 55 empleados, llegando a tener en una oportunidad 57. Todos estos para la atención de un promedio de 60 pasajeros, los que en contadas ocasiones han llegado al máximo de capacidad que es 110 pasajeros. Este establecimiento y servicio, brinda una mala atención y pésima alimentación, deficiente administración, pese a su categoría de internacional, y fue un centro de activistas políticos comunistas y socialistas que momentáneamente están inactivos. -

d).- Servicios disminuidos: Armada Nacional, Fuerza Aérea, Carabineros de Chile y Dirección de Aeronáutica.

e).- Otros servicios: Se mantienen iguales. -

Pasando a otro punto, falta aliciente a la empresa privada tales como: talleres, maestranzas, hoteles, moteles, peluquerías, comercio en general, etc., en que el pascuense no está capacitado o no ejerce por tener otras labores mas fáciles o lucrativas, tales como buceo, explotación del turismo y artesanía sobre las cuales tiene el monopolio por las diversas disposiciones que prohíben el trabajo a los chilenos continentales. -

Falta de incentivo económico para los profesionales capacitados. La Ley $\mathrm{N}^{\circ}$ 16.441 , otorga el $200 \%$ de gratificación de zona a los empleados fiscales venidos del continente, pero por política electorera en 1972 y año actual, éste beneficio se amplió a todos los obreros contratados en Isla de Pascua (especialmente pascuenses), iniciándose en el Mopt, luego Corfo y Honsa, y se continúa en esta política con gran número de beneficiados. Esta medida puso término al incentivo económico al crear una hiperinflación por aumento de circulante y pérdida de la agricultura y pesca, ya que los dedicados a estas labores pasaron a la obra pública o área fiscal, creando el desabastecimiento de alimentos.

Esta medida no atrae a personas capacitadas ya que no compensan los sacrificios que deben afrontarse en ésta: a) aislamiento (un avión semanal a $\mathrm{E}^{\circ} 26,000 \mathrm{el}$ pasaje por persona y próximo a ser elevado); b) desprecio y mal trato por parte de los pascuenses; c) desconexión con los adelantos del momento, atraso profesional; d) neurosis depresiva que sufre todo continental y que reacciona con tratamiento médico; e) mala habitación, no hay casas que arrendar y las fiscales son de tipo provisorio o de emergencia; f) falta absoluta de recreación ya que conocidos los monumentos arqueológicos y playas, no hay otra clase de distracción; g) altísimo costo de la vida por la gran inflación, producto de la facilidad con que el pascuense gana los escudos y que gasta con igual facilidad, por no preocuparse del futuro. -

Con una renta mensual menor se puede vivir mejor y sacar mas provecho en Santiago u otras ciudades del continente. -

El decir que la Isla es plácida y especial para mejorar de las afecciones nerviosas es un mito, creado por los turistas y los funcionarios comisionados a esta Isla que 
en realidad gozan los pocos días de su permanencia de las atenciones a que son objetos por parte de los funcionarios a quienes visitan, los tour por la Isla y demás atenciones propias de los pascuenses interesados. Pero la realidad es diferente, al poco estar viviendo se introduce en la vida ordinaria de la Isla, plagada de chismes, malas intenciones, egoísmos y acciones propias de pueblos chicos y como resultante se producen las neurosis depresivas y de angustia en un alto porcentaje. -

Sería largo seguir enumerando detalles y otros antecedentes sobre el aspecto administrativo y formas de vida de Isla de Pascua y solamente se ha limitado a relatarse en forma somera la impresión personal del infrascrito en el transcurso de un año y siete meses de permanencia y trabajo en ésta, pero estoy seguro que las modificaciones y cambios que se efectuarán en la administración local por el actual Gobierno, redundará en un verdadero y significativo desarrollo para este lejano territorio Nacional. -

Acompaño copias de los Oficios reservados que a continuación se detallan:

№ 22 , de 5.X.973.- Al Sr. Director de la V zona de Salud;

$\mathrm{N}^{\circ} 23$, de 5.X.973.- Al Sr. Vice-Pdte. Del Banco Estado de Chile;

$\mathrm{N}^{\circ} 24$, de 5.X.973.- Al Sr. Vice.Pdte. Ejecutivo de la E.C.A.-

$\mathrm{N}^{\circ} 25$, de 5.X.973.- Al Sr. Gerente General de la Corfo;

$\mathrm{N}^{\circ} 26$, de 5.X.973.- Al Sr. Vice.Pdte. de Indap. ;

$\mathrm{N}^{\circ} 27$, de 5.X.973.- Al Sr. Subsecretario de OO.PP y transporte; y

No 28 , de 5.X.973.- Al Sr. Director de la Comisión Nacional de Desarrollo de Isla de Pascua. - (Este oficio fue enviado en correspondencia oficial de Carabineros al día 6 del actual y que no habría sido recibido por UD.-)

Saluda atentamente a UD.-

OMAR J. FUENZALIDA TOBAR

Mayor de carabineros

GOBERNADOR.

\section{Bibliografía}

Delsing, RIET, Articulating Rapa Nui: Polynesian Cultural Politics in a Latina American Nation-State, Universty of Hawai'Press, Honolulu, 2015.

Fischer, STEVEn R., Island at the end of the world. The turbulent history of Easter Island, Reaktion Books, London, 2005.

Foerster, Rolf y Montecino, Sonia, "Las tramas políticas de Isla de Pascua durante el Gobierno de la Unidad Popular (UP): 1970-1973", Apuntes del Museo (Biblioteca Mulloy, Isla de Pascua), No 2, pág. 56-116, 2013.

Informe Comisión Verdad Histórica y Nuevo Trato, "Informe preparado por los señores Mario Tuki Hay, Tera’i Hucke Atán, Raúl Teao Hey, Antonio Tepano Hito y la señorita 
Makari Zenteno”, pp. 447-482, 2003. (Disponible en http://biblioteca.serindigena. org/libros_digitales/cvhynt/v_iii/t_i/pueblos/informe_consejo_rapa_nui_(6).pdf)

McCall, Grant, "El pasado en el presente de Rapanui (Isla de Pascua)", Culturas de Chile. Etnografía. Sociedades Indígenas contemporáneas y su ideología, Editorial Andrés Bello, Santiago, p. 17-46, 1996.

Rapanui. Tradición y sobrevivencia en la Isla de Pascua. Easter Island Foundation, California, 1998.

Porteous, Douglas, The Modernization of Easter Island, University of Victoria (Canada), Western Geographical Series Vol. 19, 1981. 